\title{
HETEROGENEOUS AGENT MODELS IN FINANCIAL MARKETS: A NONLINEAR DYNAMICS APPROACH
}

\author{
XUE-ZHONG HE ${ }^{\dagger}$, YOUWEI LI ${ }^{\S}$, AND MIN ZHENG ${ }^{\sharp}$, \\ $\dagger$ UTS Business School, University of Technology Sydney, PO Box 123, Broadway, NSW 2007, Australia \\ $\S$ Hull University Business School, University of Hull, Hull, UK \\ ${ }^{\sharp}$ China Institute for Actuarial Science, Central University of Finance and Economics, Beijing 100081, China
}

Abstract. Studies on financial markets have accumulated consistent evidences of stylized facts and anomalies, which can be characterized by stochastic switching among different co-existing market states but yet difficult to reconcile with traditionally rational expectation theory. When agents are heterogeneous and boundedly rational, recent developments on the role of the adaptive behavior of interacting heterogeneous agents in financial markets have provided a nonlinear dynamics channel to such co-existence of different market states, shedding light into these stylized facts and anomalies. This survey focuses on the nonlinear dynamics approach to model the feedback of evolutionary dynamics of heterogeneous agents and to characterize the underlying mechanisms of the stylized facts and anomalies in financial markets, of which the authors and several coauthors have contributed in several papers.

Keywords: Stylized facts, anomalies, heterogeneous beliefs, nonlinear dynamics, stability and bifurcation

Date: Latest version: November 29, 2018.

Acknowledgements: Financial support from the National Natural Science Foundation of China (No. 71571197), the 111 Project (No. B17050) and Beijing Natural Science Foundation (No. 9152016) are also gratefully acknowledged.

घ Corresponding author: mzheng@cufe.edu.cn. 


\section{INTRODUCTION}

The traditional view of homogeneity and perfect rationality in finance and economics faces various theoretical limitations and empirical challenges. As suggested by Heckman (2001), the 2000 Nobel Laureate in economics, "the most important discovery was the evidence on pervasiveness of heterogeneity and diversity in economic life. When a full analysis was made of heterogeneity in response, a variety of candidate averages emerged to describe the average person, and the longstanding edifice of the representative consumer was shown to lack empirical support." Empirically, financial markets show some common features, the so-called stylized facts ${ }^{1}$, and market anomalies, including cross-section momentum, the short-run momentum and long-run reversal. They are difficult to be accommodated and explained within the standard paradigm of rational expectations.

Many market anomalies can be characterized by the coexistence of very often puzzling and even controversial market phenomena, such as persistent high and low volatility clusterings, momentum in the short run and reversal in the long run, price bubbles and crashes, and more generally the controversial views on efficient market hypothesis (Fama, 1970, 2014 and Shiller, 2003, 2014). Traditional rational expectation equilibrium (REE) literature focuses on the role of homogeneous private information (Grossman and Stiglitz, 1980 and Admati, 1985). However, with increasing uncertainty in modern financial markets, information becomes so complex and heterogeneous that some investors tend to have comparative advantages in different types of information than others. Recent REE literature has pointed the nature of interaction among heterogeneously informed investors as a key point in understanding how financial markets work (Admati and Pfleiderer, 1987 and Goldstein and Yang, 2015). However this literature is mainly focused on a linear equilibrium in a static setup. Though some recent studies have showed the possible existence of multiple equilibrium static states, the characterization of the co-existence of different market states and the endogenous switching mechanism among the states have not be well explored. More importantly, the REE faces a great challenge to incorporate the evolutionary dynamics of price and market population of heterogeneous investors.

With multidimensional information uncertainty and endogenous information, investors are prevented from forming rational expectation and solving life-time optimization problems. Instead they are bounded rational when making their optimal decision based on their limited information and beliefs (see, for example, Sargent 1993 and Shefrin 2005). Such bounded rationality and investor heterogeneity can

\footnotetext{
${ }^{1}$ They include excess volatility, excess skewness, fat tails, volatility clustering, long range dependence in volatility, and various power-law behavior, see Pagan (1996), and Lux (2009).
} 
have profound consequences for the interpretation of empirical evidences and the formulation of economic policies. Also, the uses of fundamental and non-fundamental analyses such as trend extrapolation (or momentum trading) by financial market professionals are well documented ${ }^{2}$. Over the last three decades, these empirical evidences, unconvincing justification of the assumption of unbounded rationality and investor psychology, have led to the incorporation of heterogeneity in information, beliefs and bounded rationality into financial market modelling using the nonlinear dynamics approach. This has led to fruitful development in financial economics, empirical finance, and market practice.

The nonlinear dynamics approach goes back to the contributions of Day and Huang (1990), Chiarella (1992), De Grauwe, Dewachter and Embrechts (1993), Lux (1995), Brock and Hommes (1998), inspired by the pioneering work of Zeeman (1974) and Beja and Goldman (1980). This approach views a financial market as a result of nonlinear interaction of heterogeneous investors with different expectations that are characterized by the expectation feedback mechanism. Namely, agents' decisions are based upon the predictions of endogenous variables whose actual values are determined by the expectations of agents. This results in the co-evolution of population dynamics of investors with different beliefs and asset prices over time. This modelling approach has led some nonlinear models to characterize various endogenous mechanisms of market fluctuations, puzzling anomalies, and financial market crisis.

This survey stresses the underlying mechanisms for some stylized facts and market anomalies by focusing on the nonlinear dynamics approach developed in agentbased models in financial markets. With different groups of traders having different expectations about future prices ${ }^{3}$, asset price fluctuations can be caused endogenously. For instance, by considering two types of traders, typically fundamental and non-fundamental (such as trend following or momentum) investors, Beja and Goldman (1980), Day and Huang (1990), Chiarella (1992), Lux (1995) and Brock and Hommes (1998) were amongst the first to have shown that the interaction of agents with heterogeneous expectations, especially the population evolution and expectation feedback mechanism among them, may lead to market instability. Within this framework, adaptation, evolution, heterogeneity, and even learning can be incorporated $^{4}$. The resulting financial market models tend to have coexistence of different

\footnotetext{
${ }^{2}$ See, for example, Allen and Taylor (1990) for foreign exchange markets and Menkhoff (2010) for fund managers.

${ }^{3}$ The heterogeneous expectations can be driven by heterogeneous information and market microstructure essentially. However, to highlight the nonlinear approach, the agent-based literature often models the heterogeneous expectations through different trading behavior.

${ }^{4}$ See for example Hommes (2001), Chiarella and He (2002, 2003b), Chiarella, Dieci and Gardini (2002), and Chiarella, He and Hommes (2006).
} 
market dynamics characterized by different stability and bifurcations of the underlying deterministic models. Triggered by noisy shocks, market dynamics can display stochastic switching among different market states. This broadened framework has successfully explained various types of market behavior, such as the long-term swing of market prices from the fundamental price, asset bubbles and market crashes. It also shows a potential to characterize and explain the stylized facts (see, for example, Gaunersdorfer and Hommes 2007, LeBaron 2006) and various power law behavior (for instance, Alfarano, Lux and Wagner 2005, He and Li 2008, and Zheng, Liu and Li, 2018) observed in financial markets ${ }^{5}$.

This paper surveys the nonlinear dynamics approach in agent-based models for the underlying mechanisms of generating various stylized facts and market anomalies in equity, housing, and exchange rate markets, of which the authors and several coauthors have contributed in several papers. The coexistence of different market states is through different types of bifurcations, such as Chenciner/Bautin, pitchfork and saddle-node bifurcations. We illustrate that, triggering the endogenous switching among different market states, the interaction of multiple states (attractors) of deterministic dynamics and noise processes can generate volatility clustering and volatility spill-over in equity markets, booming and busting in housing markets, and puzzling anomalies in foreign exchange rate markets.

The paper is organized as follows. We first discuss some discrete-time agentbased financial market models in stock markets in Section 2 and in housing markets in Section 3. We then extend the discussion to continuous-time models of stock and foreign exchange markets in Sections 4 and 5, respectively. Section 6 concludes with some discussion on future research.

\section{Single Risky Asset Models in Discrete Time}

Stochastic volatility clustering that large (small) price changes tend to be followed by large (small) price changes of either sign is one of the most documented stylized facts in financial markets. Though the widespread ARCH and GARCH models have provided rich econometric techniques to characterize these features successfully, theoretical studies often rely on exogenous time-varying preference, information arriving, even on specific volatility regime shifts. In this section, to illustrate the nonlinear mechanism and explanatory power to the volatility clustering, we discuss a single risky asset pricing model of He, Li and Wang (2016) that has been developed from Dieci, Foroni, Gardini and He (2006), provide some of the underlying mathematical and economic mechanisms to the volatility clustering. For the

\footnotetext{
${ }^{5}$ We refer to Hommes (2006), LeBaron (2006), Chiarella, Dieci and He (2009), Hommes and Wagener (2009), Westerhoff (2009), Chen, Chang and Du (2012), Hommes (2013), He (2014), and Dieci and He (2018) for surveys of these developments in this literature.
} 
estimation and empirical study of the model, see Li, Donkers and Melenberg (2010) and $\mathrm{He}$ and $\mathrm{Li}(2015$ b 2017). Most of this literature follows the seminal work of Brock and Hommes $(1997,1998)$ and develops various heterogeneous agent models (HAMs) to incorporate adaptive evolution, heterogeneity, and learning with both Walrasian and market maker market clearing scenarios ${ }^{6}$.

2.1. A HAM of Asset Prices with Heterogeneous Expectations. Consider a financial market with one risky asset and one risk free asset. Let $r$ be the constant risk free rate, $p_{t}$ the price, and $d_{t}$ the dividend of the risky asset at time $t$. Assume that there are four types of agents, fundamental traders, trend followers, noise traders, and a market maker. Let $n_{3}$ be market fraction of the noise traders and $n_{1}$ and $n_{2}$ be the fractions of the fundamentals traders and trend followers respectively among the market fraction of $1-n_{3}$. To explore different mechanisms, we first consider the fractions of the fundamentals traders and trend followers to be fixed exogenously in this subsection and then be modeled endogenously in the following subsection.

Let $R_{t+1}=p_{t+1}+d_{t+1}-R p_{t}$ be the excess return and $R=1+r$. The order flow $z_{h, t}$ of type- $h$ investors from $t$ to $t+1$ is modelled by ${ }^{7}$

$$
z_{h, t}=\frac{E_{h, t}\left(R_{t+1}\right)}{a_{h} V_{h, t}\left(R_{t+1}\right)},
$$

where $E_{h, t}$ and $V_{h, t}$ are the conditional expectation and variance at time $t$, respectively, and $a_{h}$ is the risk aversion coefficient of type $h$ traders; here $h=1$ represents fundamental traders and $h=2$ trend followers. The order flow of the noise traders $\xi_{t} \sim N\left(0, \sigma_{\xi}^{2}\right)$ is an i.i.d. random variable. Then the population weighted average order flow is given by

$$
Z_{e, t}=\left(1-n_{3}\right) n_{1} z_{1, t}+\left(1-n_{3}\right) n_{2} z_{2, t}+n_{3} \xi_{t} .
$$

To simplify the analysis, the market price is determined by the market maker (Chiarella and He (2003b)) via

$$
p_{t+1}=p_{t}+\lambda Z_{e, t}=p_{t}+\mu z_{e, t}+\zeta_{t},
$$

where $z_{e, t}=n_{1} z_{1, t}+n_{2} z_{2, t}, \mu=\lambda\left(1-n_{3}\right), \zeta_{t} \sim N\left(0, \sigma_{\zeta}^{2}\right)$ with $\sigma_{\zeta}=\lambda n_{3} \sigma_{\xi}$ and $\lambda$ denotes the price adjustment speed (and risk tolerance) of the market maker.

\footnotetext{
${ }^{6}$ For example, Farmer and Joshi (2002) and Chiarella and He (2003b) extend the framework to a market maker scenario; Chiarella and He $(2002,2003 a)$ consider the impact of heterogeneous risk aversion and learning; Chiarella et al. (2006) examine the dynamics of moving averages (MA).

${ }^{7}$ The demand function can be motivated by maximizing the expected CARA utility directly or investor behavior indirectly.
} 
For the beliefs of the fundamental traders, their conditional mean and variance are assumed to follow

$$
E_{1, t}\left(p_{t+1}\right)=p_{t}+(1-\alpha)\left[E_{t}\left(p_{t+1}^{*}\right)-p_{t}\right], \quad V_{1, t}\left(p_{t+1}\right)=\sigma_{1}^{2},
$$

where $p_{t}^{*}$ is the fundamental value of the risky asset following a random walk ${ }^{8}$ and hence $E_{t}\left(p_{t+1}^{*}\right)=p_{t}^{*}$. Here $(1-\alpha)$ measures the speed of price adjustment towards the fundamental price with $0<\alpha<1$. A higher $\alpha$ indicates less confidence on the convergence to the fundamental price, leading to a slower adjustment of the market price to the fundamental. For the trend followers, their beliefs follow

$$
E_{2, t}\left(p_{t+1}\right)=p_{t}+\gamma\left(p_{t}-u_{t}\right), \quad V_{2, t}\left(p_{t+1}\right)=\sigma_{1}^{2}+b_{2} v_{t},
$$

where $u_{t}$ and $v_{t}$ are sample mean and variance respectively, $\gamma \geq 0$ measures the extrapolation of the trend, and $b_{2} \geq 0$ measures the sensitivity to the sample variance $^{9}$. We model the sample mean and variance as limiting mean and variance of the geometric decay processes when the memory lag tends to infinity,

$$
u_{t}=\delta u_{t-1}+(1-\delta) p_{t}, \quad v_{t}=\delta v_{t-1}+\delta(1-\delta)\left(p_{t}-u_{t-1}\right)^{2}
$$

where $\delta \in(0,1)$ measures the geometric decay rate. For simplicity, it is assumed that investors share a homogeneous belief about the dividend process $d_{t}$, which is i.i.d. and normally distributed with mean $\bar{d}$ and variance $\sigma_{d}^{2}$. Denote by $p^{*}=p_{0}^{*}=\bar{d} / r$ the long-run fundamental price.

Then the asset price dynamics are determined by the following random dynamic system in discrete-time,

$$
\left\{\begin{aligned}
p_{t+1} & =p_{t}+\mu\left(n_{1} z_{1, t}+n_{2} z_{2, t}\right)+\zeta_{t}, \quad \zeta_{t} \sim \mathcal{N}\left(0, \sigma_{\zeta}^{2}\right), \\
u_{t} & =\delta u_{t-1}+(1-\delta) p_{t}, \\
v_{t} & =\delta v_{t-1}+\delta(1-\delta)\left(p_{t}-u_{t-1}\right)^{2} .
\end{aligned}\right.
$$

2.2. Volatility Clustering via Neimark-Sacker Bifurcation. The above model (2.4) was developed in Dieci et al. (2006). When there are no fundamental and market noises, that is, $\sigma_{\varepsilon}=\sigma_{\zeta}=0$, then system (2.4) becomes a deterministic dynamical system. Dieci et al. (2006) show that this deterministic model can exhibit the following price dynamics, characterized by the local stability of the fundamental price and its bifurcation.

\footnotetext{
${ }^{8}$ The random walk fundamental price can be modelled either by $p_{t+1}^{*}=p_{t}^{*} \exp \left(-\frac{\sigma_{\varepsilon}^{2}}{2}+\sigma_{\varepsilon} \varepsilon_{t+1}\right)$ or $p_{t+1}^{*}=p_{t}^{*}\left(1+\sigma_{\varepsilon} \varepsilon_{t+1}\right)$, where $\varepsilon_{t} \sim \mathcal{N}(0,1), \sigma_{\varepsilon} \geq 0$ and $p_{0}^{*}=p^{*}>0 ; \varepsilon_{t}$ is independent of the noise process $\xi_{t}, \sigma_{1}^{2}$ is constant. The specification is independent of the nonlinear mechanism of the underlying deterministic model and the characterization of volatility clustering.

${ }^{9}$ With the specification in (2.3), the nonlinearity is introduced through the time-varying sample variance and the demand function.
} 
Proposition 2.1. Denote $\rho=a_{2} / a_{1}, Q=2 a_{2} \sigma_{1}^{2}\left(1+r^{2}\right), K=\frac{\mu}{Q}\left[n_{1} \rho(\alpha-R)+n_{2}(1-\right.$ $R)](<0)$ and $\gamma^{*}=(R-1)+(Q(1-\delta)) / \delta \mu n_{2}+\rho n_{1}(R-\alpha) / n_{2}$. The underlying deterministic system of (2.4) has a unique fundamental steady state $(p, u, v)=\left(p_{0}^{*}, p_{0}^{*}, 0\right)$. Assume $-2<K<0$. The fundamental steady state is locally asymptotically stable for $\gamma \in\left(0, \gamma^{*}\right)$, and it undergoes a Neimark-Sacker bifurcation at $\gamma=\gamma^{*}$, that is, there is an invariant curve near the fundamental steady state. Moreover, the bifurcated closed invariant curve is forward and stable.

Proposition 2.1 shows that the fundamental steady state price $\bar{p}$ is locally stable when the activity of the trend followers, measured by $\gamma$, is not strong (so that $\left.\gamma<\gamma^{*}\right)$. That is, when the market is dominated by the fundamental traders, the fundamental price is stabilized. However, when the market is dominated by the trend followers, the steady state price is destabilized. The consequence of the changing dominance is characterized by the Neimark-Sacker bifurcation, generating the local stability of the fundamental price and periodic oscillation around the fundamental price. Essentially, on the parameter space of the deterministic model, near the Neimark-Sacker-bifurcation boundary, the fundamental steady state can be locally stable but globally unstable. Due to the nature of the Neimark-Sacker bifurcation, such global instability leads to switching between the locally stable fundamental price and the periodic oscillations around the fundamental price. Then triggered by the fundamental and market noises, He and Li (2007) demonstrate that the interaction of fundamentalists and risk-adjusted trend chasing from the trend followers, and the interplay of noisy fundamental and demand processes and the underlying deterministic dynamics, can be the source of the stylized facts observed in financial markets, including volatility clustering and power-law behavior.

\subsection{Volatility Clustering via the Coexistence of Attractors and Chenciner}

Bifurcation. To explore the second mechanism on volatility clustering, we introduce the adaptive switching to endogenize the market fractions of the fundamental and trend following traders.

Let $Q_{i, t}(i=1,2)$ be the market fractions of the fundamental and trend following traders, respectively, having fixed components, $n_{1}$ and $n_{2}$, and time-varying components, $n_{1, t}$ and $n_{2, t}=1-n_{1, t}$. That is, $\left(1-n_{3}\right)\left(n_{1}+n_{2}\right)$ represents the proportion of traders who do not change their strategies over time, while $\left(1-n_{3}\right)\left[1-\left(n_{1}+n_{2}\right)\right]$ the proportion of traders who may switch between the two types. Therefore the market fractions of fundamental and trend following traders $\left(Q_{1, t}, Q_{2, t}\right)$ at time $t$ are expressed by $Q_{1, t}=\left(1-n_{3}\right)\left[n_{1}+\left(1-n_{1}-n_{2}\right) n_{1, t}\right]$ and $Q_{2, t}=\left(1-n_{3}\right)\left[n_{2}+(1-\right.$ $\left.\left.n_{1}-n_{2}\right) n_{2, t}\right]$. Denote $n_{0}=n_{1}+n_{2}, m_{0}=\left(n_{1}-n_{2}\right) / n_{0}$ and $m_{t}=n_{1, t}-n_{2, t}$. Then 
the market fractions at time $t$ can be rewritten as

$$
\left\{\begin{array}{l}
Q_{1, t}=\frac{1}{2}\left(1-n_{3}\right)\left[n_{0}\left(1+m_{0}\right)+\left(1-n_{0}\right)\left(1+m_{t}\right)\right] \\
Q_{2, t}=\frac{1}{2}\left(1-n_{3}\right)\left[n_{0}\left(1-m_{0}\right)+\left(1-n_{0}\right)\left(1-m_{t}\right)\right]
\end{array}\right.
$$

To characterize the adaptive switching behavior of traders, denote by $\pi_{h, t+1}$ the realized profit, or excess return, between $t$ and $t+1$ for type $h$ traders: $\pi_{h, t+1}=$ $z_{h, t}\left(p_{t+1}+d_{t+1}-R p_{t}\right)=W_{h, t+1}-R W_{h, t}$ for $h=1,2$. Following Brock and Hommes $(1997,1998)$, the proportion of "switching" traders at time $t+1$ can be determined by

$$
n_{h, t+1}=\frac{\exp \left[\beta\left(\pi_{h, t+1}-C_{h}\right)\right]}{\sum_{i=1}^{2} \exp \left[\beta\left(\pi_{i, t+1}-C_{i}\right)\right]}, \quad h=1,2,
$$

where $C_{h} \geq 0$ is a fixed cost associated with strategy $h$, parameter $\beta$ is the intensity of choice measuring the switching sensitivity of the population of the adaptively rational traders to the better profitable strategy. From $m_{t+1}=n_{1, t+1}-n_{2, t+1}$, we have

$$
m_{t+1}=\tanh \left\{\frac{\beta}{2}\left[\left(\pi_{1, t+1}-\pi_{2, t+1}\right)-\left(C_{1}-C_{2}\right)\right]\right\} .
$$

Together with (2.5) the market fractions is determined by

$$
m_{t}=\tanh \left\{\frac{\beta}{2}\left[\left(z_{1, t-1}-z_{2, t-1}\right)\left(p_{t}+D_{t}-R p_{t-1}\right)-\left(C_{1}-C_{2}\right)\right]\right\} .
$$

Note that, in this case, $Z_{e, t}=q_{1, t} z_{1, t}+q_{2, t} z_{2, t}$ and $q_{1, t}=Q_{1, t} /\left(1-n_{3}\right)=\left[n_{0}(1+\right.$ $\left.\left.m_{0}\right)+\left(1-n_{0}\right)\left(1+m_{t}\right)\right] / 2$ and $q_{2, t}=Q_{2, t} /\left(1-n_{3}\right)=\left[n_{0}\left(1-m_{0}\right)+\left(1-n_{0}\right)\left(1-m_{t}\right)\right] / 2$. The corresponding adaptive model of asset pricing and population dynamics lead to the following mechanism on the co-existence of a locally stable fundamental steady state and a periodic cycle through a Chenciner bifurcation, see He, Li and Wang (2016) for the details.

Proposition 2.2. The deterministic system has a unique fundamental steady state $(p, u, v, m)=(\bar{p}, \bar{p}, 0, \bar{m})$. Under some conditions (see Theorem 3.2 in He, Li and Wang (2016)), the fundamental steady state $(\bar{p}, \bar{p}, 0, \bar{m})$ is locally asymptotically stable for $\gamma \in\left(0, \gamma^{* *}\right)$, undergoes a Neimark-Sacker bifurcation at $\gamma=\gamma^{* *}$, that is, there is an invariant curve near the fundamental steady state. Moreover, the bifurcated closed invariant curve is forward and stable when the first Lyapunov coefficient $a_{2}(0)<0$ and backward and unstable when $a_{2}(0)>0$, and a Chenciner bifurcation takes place when $a_{2}(0)=0$.

He, Li and Wang (2016) provide some numerical simulations to illustrates two different types of Neimark-Sacker bifurcation in Fig. 1 for the switching model. Depending on the sign of the first Lyapunov coefficient $a_{2}(0)$, we observe a forward and stable bifurcation when $a_{2}(0)<0$, meaning that the bifurcated invariant circle 

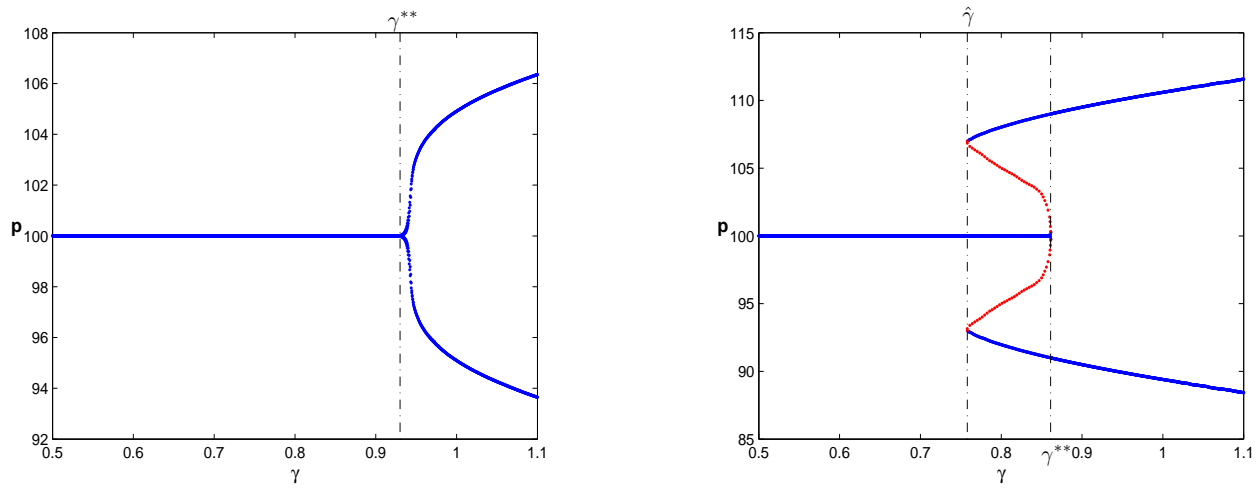

FIGURE 1. The bifurcation diagrams of the market price with respect to $\gamma$.
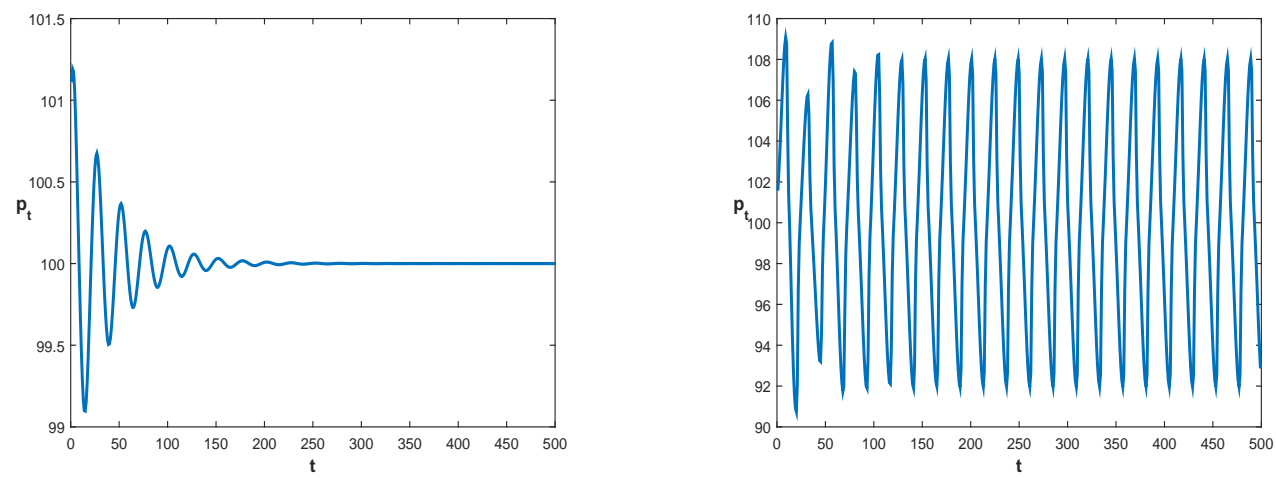

Figure 2. Coexistence-The deterministic trajectories of price versus time for $\left(p_{0}, u_{0}, v_{0}, m_{0}\right)=(\bar{p}+1, \bar{p}, 0, \bar{m})$ (left) and $\left(p_{0}, u_{0}, v_{0}, m_{0}\right)=$ $(\bar{p}+1, \bar{p}-1,0, \bar{m})$ (right).

occurring for $\gamma>\gamma^{* *}$ is locally stable. In this case, as $\gamma$ increases and passes $\gamma^{* *}$, the fundamental steady state becomes unstable and the trajectory converges to an invariant circle bifurcating from the fundamental steady state. As $\gamma$ increases further, the trajectory converges to invariant circles with different sizes. This is illustrated in Fig. 1 (left). However, when $a_{2}(0)>0$, the bifurcation is backward and unstable, meaning that the bifurcated invariant circle occurring at $\gamma=\gamma^{* *}$ is unstable. This is illustrated in Fig. 1 (right), showing a continuation of the unstable bifurcated circles as $\gamma$ decreases initially until it reaches a critical value $\hat{\gamma}$, which is indicated by the two red curves of the bifurcating circles for $\hat{\gamma}<\gamma<\gamma^{* *}$. Then as $\gamma$ increases from the critical value $\hat{\gamma}$, the bifurcated circles becomes forward and stable. This is illustrated by the two blue curves, which are the boundaries of the bifurcating circles, for $\gamma>\hat{\gamma}$. Therefore, the stable steady state coexists with the stable 'forward extended' circles for $\hat{\gamma}<\gamma<\gamma^{* *}$, in between there are backward extended unstable circles. For $\hat{\gamma}<\gamma<\gamma^{* *}$, even when the fundamental steady state 

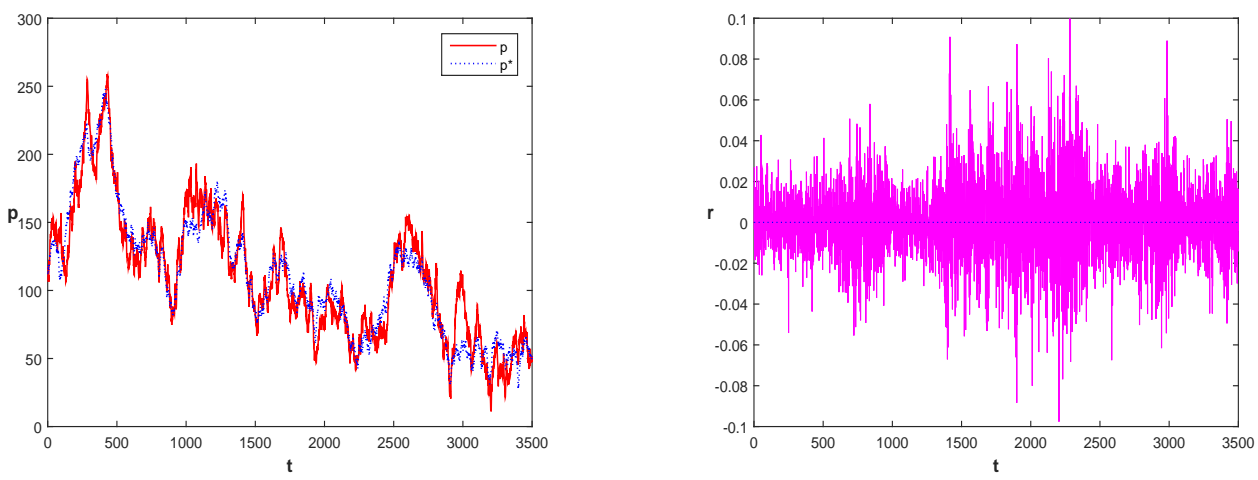

Figure 3. The time series of the market price (red solid line) and the fundamental price (blue dotted line) on the left panel and the market returns on the right panel of the stochastic model.

is locally stable, prices need not converge to the fundamental value, while may settle down to a stable limit circle, corresponding to 'volatility clustering region'. Such coexistence of locally stable fundamental price and bifurcated circle is illustrated in Fig. 2 with different initial values.

When buffeted with noises, He, Li and Wang (2016) then show numerically that the interaction of the deterministic dynamics and noise processes can endogenously generate volatility clustering and long-range dependence in volatility observed in financial markets, illustrated in Fig. 3. Economically, with strong trading activities of either the fundamental investors or the trend followers, market price fluctuates around either the fundamental value with low volatility or a cyclical price movement with high volatility depending on market conditions. The fundamental noise and noise traders then trigger irregular switchings between two volatility regimes and therefore lead to volatility clustering.

He and Li $(2015 b, 2017)$ conduct econometric analysis via Monte Carlo simulations and show that the autocorrelations of returns, absolute returns and squared returns of the model developed above share the same pattern as those of the DAX 30. By characterizing the power-law behavior of the DAX 30, they find that the estimates of the power-law decay indices, the (FI)GARCH parameters, and the tail index of the model closely match those of the DAX 30. Dieci and He (2018) summarize the calibrated results of the model and provide some insights into investor behavior with respect to the two mechanisms of the volatility clustering explored above. Therefore, the model provides an economic explanation on the volatility clustering, shedding light on the understanding of volatility clustering. 


\section{Housing Market Models in Discrete Time}

The coexistence of multi-attractors is not only generated by a Chenciner bifurcation, but also born from a saddle-node bifurcation, explored in Zheng, Wang, Wang and Wang (2017). In this case, the fundamental steady state can be locally stable but globally unstable because of the appearance of a new, nonfundamental and stable steady state coming from a saddle-node bifurcation. In the following, we analyze the underlying mechanism from a saddle-node bifurcation and provide a policy implication on it (see Zheng et al., 2017 for the detail).

3.1. Nonlinear Dynamics of Housing Prices. Consider a housing market with two types of property consumers, including house buyers and investors, and one type of property developers who supply houses. At any given time, house buyers and investors decide their property demands based on their own objectives and budget constraints. In details, a house buyer really wants houses to live and his/her demand is determined by his/her ability to make down payment at the time as follows

$$
P_{n} h_{n}^{B}=M^{B}(>0)
$$

where $P_{n}$ is the housing price (without the rent) per unit of houses at time $n, h_{n}^{B}$ denotes the consumption amounts of houses demanded by the house buyer at time $n$ and $M^{B}$ represents the down payment constraints facing by the house buyer.

For an investor, he/she is a myopic mean-variance maximizer with very deep pockets and no budget or short selling constraints such that the investor's demand can be described as

$$
h_{n}^{I}=\gamma^{I}\left(P_{n+1}^{I}-P_{n}\right)
$$

where $h_{n}^{I}$ is the amount of houses the investor invests, $P_{n+1}^{I}$ is his expectation about the housing price at time $n+1$, and $\gamma^{I}(>0)$ measures the reaction intensity of the investor to his/her future expectation.

Equilibrium housing prices are derived by the market clearing condition

$$
\varphi^{B} h_{n}^{B}+\varphi^{I} h_{n}^{I}=h_{n}^{D},
$$

where $\varphi^{j} \geq 0(j=B, I)$ are constants representing the market populations of house buyers and investors corresponding to a property developer, and $h_{n}^{D}$ is the supply amount of the property developers, determined by

$$
h_{n}^{D}=\frac{P_{n}}{\mathcal{C}},
$$

where $\mathcal{C}>0$ is regarded as the development cost per unit of houses and the higher development cost, the lower supply. 
Then the equilibrium price is determined by the market clearing condition given by (3.3), satisfying

$$
m_{0} P_{n}^{2}-m_{1, n} P_{n}-m_{2}=0,
$$

where

$$
m_{0}=\frac{1}{\mathcal{C}}+\varphi^{I} \gamma^{I}, \quad m_{1, n}=\varphi^{I} \gamma^{I} P_{n+1}^{I} \text { and } m_{2}=\varphi^{B} M^{B} .
$$

This generates a one-dimensional discrete dynamic system which can be described as

$$
P_{n}=\frac{m_{1, n}+\sqrt{m_{1, n}^{2}+4 m_{0} m_{2}}}{2 m_{0}} .
$$

When $\varphi^{I}=0$, then the equilibrium price only depends on the behavior of the house buyer and property developer, that is

$$
P_{n} \equiv \bar{P}=\left(\mathcal{C} \varphi^{B} M^{B}\right)^{\frac{1}{2}}
$$

which is determined by some fundamental economic factors, such as the development cost and the down payment, and is called a benchmark price.

When $\varphi^{I} \neq 0$, similar to Dieci and Westerhoff (2012), two types of speculative beliefs are considered among investors in the housing market, extrapolation $\left(P_{n+1}^{E}\right)$ and mean-reversion $\left(P_{n+1}^{M R}\right)$. Extrapolative investors are confident in the continuation of the price trend in the next period. Their belief under the extrapolative method can be formalized as

$$
P_{n+1}^{E}=P_{n-1}+f\left(P_{n-1}-\bar{P}\right),
$$

where $f(>0)$ is the extrapolative intensity to the housing price trend. Then (3.9) implies that when the housing price is above (below) its benchmark value, trend followers optimistically (pessimistically) believe in a further price increase (decrease). Mean-reverting investors believe that the housing price cannot deviate far away from its benchmark price in the long run. Then, the mean-reverting component can be written as

$$
P_{n+1}^{M R}=P_{n-1}+g\left(\bar{P}-P_{n-1}\right),
$$

where $g \in(0,1)$ measures the mean-reverting speed adopted by investors. Equation (3.10) implies that if the housing price is above (below) its benchmark price, meanreverting investors believe that the price is overestimated (underestimated) and the future price will decrease (increase).

Thus, the impact of investors' speculative beliefs can be expressed as a nonlinear mix of different forecasting rules

$$
P_{n+1}^{I}=\omega_{n} P_{n+1}^{E}+\left(1-\omega_{n}\right) P_{n+1}^{M R},
$$

where $\omega_{n}$ and $1-\omega_{n}$ stand for the market fractions respectively of extrapolative and mean-reverting investors. 
Different investors are assumed to have social interactions and they can switch their forecasting rules with respect to market circumstances, following a formulation by He and Westerhoff (2005) and Bauer, De Grauwe and Reitz (2009). Investors seek to exploit price trends (that is, bull and bear markets). However, the more the price deviates from its benchmark value, the more agents come to the conclusion that a benchmark market correction is about to set in. As a result, an increasing number of investors opt for the mean-reverting strategy. Furthermore, the relative impact of extrapolators is formalized as

$$
\omega_{n}=\frac{1}{1+\mu\left(P_{n-1}-\bar{P}\right)^{2}},
$$

where $\mu>0$ measures the speed of switching speed. The following proposition characterizes the price dynamics of the above dynamic system.

Proposition 3.1. (Stabilities and Bifurcations) Let $f^{*}$ denote a unique positive solution of $\Delta=0$ and $f^{* *}=2\left(\varphi^{I} \gamma^{I} \mathcal{C}\right)^{-1}$. Assume $\partial^{2} P_{n} /\left.\partial P_{n-1}^{2}\right|_{\left\{P_{n-1}=P_{1}^{*}, f=f^{*}\right\}}<0$. Then

(1) When $0<f<f^{*}$, the benchmark price $\bar{P}$ is always stable.

(2) At $f=f^{*}$, a saddle-node bifurcation occurs and two non-benchmark steady states $\left(P_{1}^{*}, P_{2}^{*}\right)$ appear.

(3) When $f^{*}<f<f^{* *}, P_{1}^{*}$ is unstable and $P_{2}^{*}$ is stable while the stability of the benchmark price $\bar{P}$ keeps invariant.

(4) At $f=f^{* *}$, a transcritical bifurcation occurs.

(5) When $f>f^{* *}$, the benchmark price $\bar{P}$ becomes unstable while both $P_{1}^{*}$ and $P_{2}^{*}$ are stable.

Here $P_{1}^{*}$ and $P_{2}^{*}\left(>P_{1}^{*}\right)$ are the solutions of

$$
\mathrm{a}\left(P^{*}\right)^{3}+\mathfrak{b}\left(P^{*}\right)^{2}+\mathbb{C} P^{*}+\mathbb{d}=0
$$

where

$$
\begin{array}{r}
\mathfrak{a}=\left[\varphi^{I} \gamma^{I} g+\frac{1}{\mathcal{C}}\right] \mu, \quad \mathbb{b}=-\left[2 \varphi^{I} \gamma^{I} g+\frac{1}{\mathcal{C}}\right] \mu \bar{P}, \\
\mathbb{C}=\frac{1}{\mathcal{C}}\left(1-\mu \bar{P}^{2}\right)-\varphi^{I} \gamma^{I}\left(f-\mu g \bar{P}^{2}\right), \quad \mathbb{d}=\frac{\bar{P}}{\mathcal{C}}\left(1+\mu \bar{P}^{2}\right) .
\end{array}
$$

Then the discriminant $(\Delta)$ of $(3.13)$ is

$$
\Delta=27 \mathrm{a}^{2} \mathrm{~d}^{2}-18 \mathrm{a} \mathfrak{b} \mathbb{C} d+4 a \mathbb{c}^{3}+4 \mathfrak{b}^{3} \mathfrak{d}-\mathfrak{b}^{2} \mathbb{C}^{2} .
$$

3.2. Mechanism Analysis through Saddle-node Bifurcation. Proposition 3.1 shows that not only the benchmark price can be unstable but also system (3.7) can have multi-attractors even when the benchmark price is stable. Here, the multiattractors comes from a saddle-node bifurcation when the extrapolative intensity 


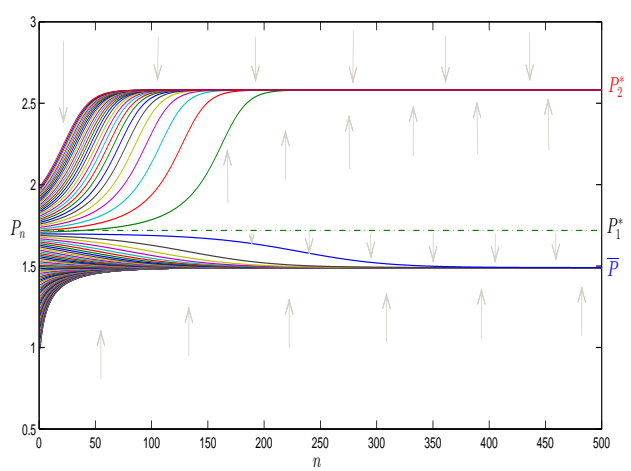

(a) Two attractors at at $f=0.9$

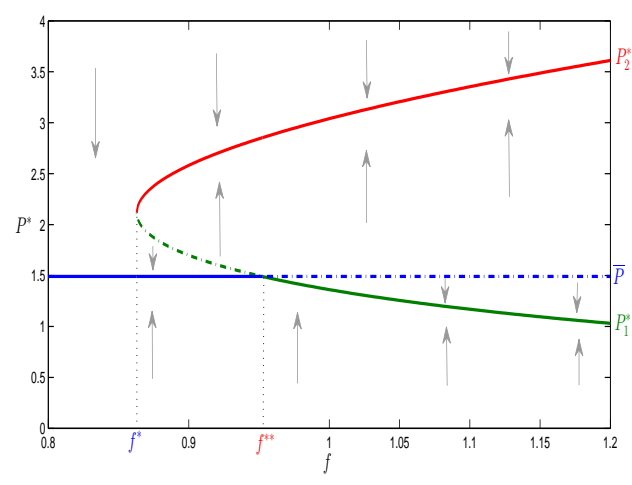

(b) Bifurcation plot

Figure 4. Here take $M^{B}=22.22, \mu=0.1, \mathcal{C}=0.1, \gamma^{I}=21, g=0.5$ and $\varphi^{I}=\varphi^{B}=1$ which correspond to the bifurcation points $f^{*}=$ 0.8629 and $f^{* *}=0.9524$. Here in (b), the dash-dot lines correspond to unstable steady states while stable steady states are given by solid lines.

$(f)$ of investors is not very strong, that is $f^{*}<f<f^{* *}$. In this situation, the stable benchmark price and a stable non-benchmark price coexist in the simple evolutionary model (3.7). The economic intuition is following: when investors' extrapolative intensity is relatively low (that is $f^{*}<f<f^{* *}$ ), for prices near the benchmark level, investors' extrapolative behavior is not strong enough to cause permanent deviations from the benchmark price. In addition, because of the existence of real demand and relatively low extrapolation, the prices cannot deviate downward from the benchmark value very far and eventually converge back to it. For the upward price trend that has deviated far away from the benchmark level, the extrapolative trend-following behavior strengthens the upward deviation of prices with stronger demands that feed back into price increases, which lets the price trend persistent and predicable. However, this up trend cannot be sustained endlessly because of meanreverting investors in the market. As the prices deviate further from the benchmark level, more and more investors form strong beliefs that the prices will mean revert. As a result, an increasing number of investors opt for the mean-reverting strategy and begin to sell houses, which increases the total house supply in the market. This creates a balance between the buying and selling sides, which stabilizes the equilibrium price at $P_{2}^{*}$. Therefore, the stable benchmark price $(\bar{P})$ and the stable nonbenchmark price $\left(P_{2}^{*}\right)$ coexist in the whole system, separated by the unstable nonbenchmark price $\left(P_{1}^{*}\right)$, as illustrated in Figure 4(a). However, if the extrapolative intensity $(f)$ of investors increases, then the stability of the benchmark price will change at $f=f^{* *}$ because of a transcritial bifurcation. The nonbenchmark price 
$P_{1}^{*}$ changes from unstable to stable. The whole system (3.7) still has two attractors, that is two stable nonbenchmark prices. The coexistence of multi-attractors means the evolutionary process of housing prices driven by investors' speculative behavior is path-dependent and depends on different initial market conditions, as illustrated in Figure 4(b). Thus, if the determinants of initial prices were some local factors, like local income, cultures, commodity prices and policy environment, then the price changes would display the localization rather than national property. This phenomenon can be used to explain one of the stylized facts in housing markets, that is most variations in housing prices are local not national.

3.3. Policy implication. Figure 4 shows that the price trend persistent and predicable. If the housing market is booming or busting, the model (3.7) shows some fundamental factors can be used to adjust the housing prices, like the down payment ratio and the development cost. However, Proposition 3.1 shows that the down payment adjustment has limited ability to affect the housing market with speculative behavior because the down payment ratio mainly can affect the real demand of house buyers. Comparatively, the development cost not only affects the supply of developers but also determines the impact of investors on housing prices because $f^{*}$ and $f^{* *}$ both depend on the development cost $(\mathcal{C})$. Therefore, it is more effective through adjusting the development cost. As follows, we use monthly Beijing housing prices from February, 2002 to February, 2016 to test the explanation power of the model (3.7) on the real housing market.

Note that system (3.7) is a deterministic nonlinear dynamic system while the real data is a stochastic time series. To match this gap, based on the idea of He and Li $(2015 b)$, a noise term is introduced in (3.7) as follows

$$
P_{n}=G\left(P_{n-1}\right)=\frac{m_{1, n}\left(P_{n-1}\right)+\sqrt{m_{1, n}^{2}\left(P_{n-1}\right)+4 m_{0} m_{2}}}{2 m_{0}}+\varepsilon_{n},
$$

where $\varepsilon_{n} \sim \mathcal{N}\left(0, \sigma_{\varepsilon}\right)$ captures a market noise either driven by unexpected news about fundamentals, or representing noise created by noise traders.

By a genetic algorithm, the parameters in system (3.14) can be calibrated shown in Table 1. It shows that during the period from February, 2002 to February, 2016, the extrapolative intensity $(f)$ of investors is very strong and is much bigger than the saddle-node and transcritical bifurcation points $\left(f^{*}\right.$ and $\left.f^{* *}\right)$ both, which means that the benchmark price is unstable and the price will deviate from it upwards because its initial price is bigger than the benchmark price. This gives one of the explanations to the booming phenomenon of the Beijing housing market from the viewpoint of investors' behavior.

For the continuously increasing trend of the Beijing housing prices, the Beijing government has taken many measures to cool down the Beijing housing market. For 


\begin{tabular}{ccccccccc}
\hline Time period & $\varphi^{I} \gamma^{I}$ & $m_{2}$ & $\mu$ & $g$ & $\mathcal{C}$ & $f$ & $f^{*}$ & $f^{* *}$ \\
\hline \hline $2002-2016$ & 1.2486 & 0.1562 & 0.1002 & 0.0884 & 1.9378 & 0.9543 & 0.6236 & 0.8266 \\
\hline $2002-2010$ & 1.0617 & 0.1937 & 0.3497 & 0.0526 & 1.5714 & 1.5212 & 0.9982 & 1.1988 \\
\hline $2010-2016$ & 1.7090 & 1.8027 & 0.1925 & 0.4011 & 1.7454 & 0.9740 & 0.6392 & 0.6705 \\
\hline \multicolumn{8}{c}{ TABLE } & 1. Optimal parameters
\end{tabular}

example, from April, 2010, the government took steps to cool the housing market by increasing the down payment ratio. However, the data discovers that these measures have little impact on the Beijing housing prices. Using the model (3.14), some insights about the ineffectivity of adjusting the down payment ratio can be revealed. In fact, the parameters of (3.14) can be calibrated corresponding to the situations before and after the housing policy adjustments. From Table 1, before the policy change, the extrapolative behavior is very salient, which makes the benchmark price unstable because of $f>f^{* *}$. By contrast, after increasing the down payment ratio, the extrapolative intensity is decreased while the mean-reverting speed is increased. It seems that it would cool the market down because the mean-revering behavior has the role of stabilizing the housing price and the extrapolative behavior is weakened. However, in the housing market, all the parameters, not just one, play a part together. Hence, on the whole, the extrapolative and mean-reverting behavior cannot cool the market down because the extrapolative intensity $(f)$ is still bigger than $f^{* *}$. This means after increasing the down payment ratio, the situation of the Beijing housing market has not been obviously changed, and the housing price cannot regress back to its benchmark price but rather deviate further away. Thus, the control strategy of housing prices based on the down payment policy is ineffective.

\section{Cross Sectional Momentum Trading in Continuous Time}

Financial markets display puzzling and even controversial anomalies and hypotheses, such as the different views on efficient market hypothesis and the volatility clusterings discussed in the previous section. Very often, we observe a time-varying dominance among the two controversial views; markets are more efficient over certain time periods but less efficient in other time periods. On the other hand, the profitability of cross sectional momentum is well documented empirically. By considering cross sectional momentum trading in a continuous-time heterogeneous agent model of two risky assets based on either economic fundamentals or price momentums, He, Li and Wang (2018) provide a general framework to characterize the coexistence of such controversial views on market efficiency and their time-varying dominance in financial markets. From a globally nonlinear dynamics point of view, 
they show that the investment constrains can cause the coexistence of two different and locally stable market states. Corresponding to the discrete case, the continuous models can also generate multi-attractors via a Bautin bifurcation, corresponding to a Chenciner bifurcation in a discrete-time model. Together with random shocks, the coexistence underlies the time-varying dominance of different market states in financial markets. This section briefs the main findings in He et al. (2018).

4.1. Cross Sectional Momentum Trading. Consider a financial market of two risky assets $(A$ and $B$ ), traded by fundamental investors, extrapolators, and noise traders. To have an intuitive and parsimonious model, the demand functions are based on agents' behavior directly by following Chiarella (1992), He and Li (2012, 2015a) and Di Guilmi, He and Li (2014). ${ }^{10}$ The fundamental investors trade based on the (log) book-to-market ratio and their excess demands are given by

$$
D_{f, t}^{i}=\tanh \left[\beta_{f}\left(F_{t}^{i}-P_{t}^{i}\right)\right], \quad i=A, B,
$$

where $F_{t}^{i}$ and $P_{t}^{i}$ are the $\log$ fundamental price and $\log$ market price of asset $i$ respectively at time $t$, and $\beta_{f}(>0)$ is a constant measuring the mean-reverting of the market price to the fundamental price. The $S$-shaped demand function $\tanh (\cdot)$ reflects various constraints faced by agents, such as the wealth constraint (the upper bound) and the short-sale constraint (the lower bound). For simplicity, the fundamental prices are assumed to satisfy

$$
\left(\begin{array}{c}
d F_{t}^{A} \\
d F_{t}^{B}
\end{array}\right)=\Sigma^{F} d W_{t}^{F}, \quad \Sigma^{F}=\left(\begin{array}{cc}
\sigma_{A, 1}^{F} & \sigma_{A, 2}^{F} \\
\sigma_{B, 1}^{F} & \sigma_{B, 2}^{F}
\end{array}\right), \quad\left(\begin{array}{c}
F_{0}^{A} \\
F_{0}^{B}
\end{array}\right)=\left(\begin{array}{c}
\bar{F}^{A} \\
\bar{F}^{B}
\end{array}\right)
$$

where $\Sigma^{F}$ is the variance-covariance matrix for fundamental returns and $W_{t}^{F}=$ $\left(W_{1, t}^{F}, W_{2, t}^{F}\right)^{\prime}$ are two independent Brownian motions.

The literature has extensively documented that many individual and institutional investors extrapolate historical returns, ${ }^{11}$ and shown that both time series momentum (or absolute momentum) and cross-sectional momentum (or relative momentum) widely used in practice can generate persistent and sizeable profits. ${ }^{12}$ Accordingly, extrapolators are also considered in the economy, who trade on short-run price trends. The extrapolators estimate price trend using a moving average of historical returns $\int_{t-\tau}^{t} d P_{u}^{i}=P_{t}^{i}-P_{t-\tau}^{i}$, where $d P_{u}^{i}$ is the (log) instantaneous return of asset $i$, and $\tau$ is the look-back period of the extrapolation. There are two

\footnotetext{
${ }^{10}$ The demands in the continuous-time setup are consistent with those deriving from heterogeneous expectations and utility maximization in discrete time heterogeneous agent models literature, see, for example, Brock and Hommes $(1997,1998)$.

${ }^{11}$ See, e.g., Vissing-Jorgensen (2004), Bacchetta, Mertens and van Wincoop (2009), Barberis (2013), Amromin and Sharpe (2014), Greenwood and Shleifer (2014) and Kuchler and Zafar (2016).

${ }^{12}$ See, e.g., Jegadeesh and Titman (1993) and Moskowitz, Ooi and Pedersen (2012) among many others.
} 
types of extrapolators, based on time series momentum (or absolute momentum) and cross-sectional momentum (or relative momentum) respectively. The demands of the absolute momentum investors for assets $A$ and $B$ are given, respectively, by

$$
D_{a, t}^{i}=\tanh \left[\beta_{a}\left(P_{t}^{i}-P_{t-\tau}^{i}\right)\right], \quad i=A, B,
$$

where $\beta_{a}(>0)$ represents the extrapolation rate of the absolute momentum investors on the future price trend.

The cross-sectional momentum strategy has been extensively documented in the literature (e.g., Jegadeesh and Titman, 1993; 2001 and Daniel and Moskowitz, 2016, among many others). It is typically conducted by longing the winners, that is, the stocks have higher past returns relative to other stocks, and shorting the losers, that is, the stocks have lower past returns relative to other stocks. Accordingly, the demands of the cross-sectional momentum investors are given by

$$
\begin{aligned}
& D_{c, t}^{A}=\tanh \left\{\beta_{c}\left[\left(P_{t}^{A}-P_{t-\tau}^{A}\right)-\left(P_{t}^{B}-P_{t-\tau}^{B}\right)\right]\right\}, \\
& D_{c, t}^{B}=\tanh \left\{\beta_{c}\left[\left(P_{t}^{B}-P_{t-\tau}^{B}\right)-\left(P_{t}^{A}-P_{t-\tau}^{A}\right)\right]\right\},
\end{aligned}
$$

where $\beta_{c}>0$ is a constant. Equation (4.4) implies that the cross-sectional momentum strategy is a zero-investment strategy by taking a long position in one asset and short position in the other asset simultaneously. The time horizon $\tau$ is assumed to be the same for both assets to be consistent with the cross-sectional momentum literature.

Therefore, both fundamental and absolute momentum investors focus on only individual asset, while the cross-sectional momentum investors trade on two assets simultaneously. The market fractions of the three types of investors who trade on asset $i$ are $\alpha_{f}^{i}$, $\alpha_{a}^{i}$ and $\alpha_{c}^{i}$ respectively, satisfying $\alpha_{f}^{i}+\alpha_{a}^{i}+\alpha_{c}^{i}=1$. Notice $\alpha_{c}^{i}$ measures the market fraction rather than the number of traders. So it can be different for the two assets even though the cross-sectional momentum investors are the same group of investors across the two risky assets.

The market maker adjusts the market price according to the aggregated excess demand

$$
\begin{aligned}
d P_{t}^{A}= & \mu^{A}\left[\alpha_{f}^{A} \tanh \left[\beta_{f}\left(F_{t}^{A}-P_{t}^{A}\right)\right]+\alpha_{a}^{A} \tanh \left[\beta_{a}\left(P_{t}^{A}-P_{t-\tau}^{A}\right)\right]\right. \\
& \left.+\alpha_{c}^{A} \tanh \left\{\beta_{c}\left[\left(P_{t}^{A}-P_{t-\tau}^{A}\right)-\left(P_{t}^{B}-P_{t-\tau}^{B}\right)\right]\right\}\right] d t+\sigma_{A}^{M} d W_{t}^{M}, \\
d P_{t}^{B}= & \mu^{B}\left[\alpha_{f}^{B} \tanh \left[\beta_{f}\left(F_{t}^{B}-P_{t}^{B}\right)\right]+\alpha_{a}^{B} \tanh \left[\beta_{a}\left(P_{t}^{B}-P_{t-\tau}^{B}\right)\right]\right. \\
& \left.+\alpha_{c}^{B} \tanh \left\{\beta_{c}\left[\left(P_{t}^{B}-P_{t-\tau}^{B}\right)-\left(P_{t}^{A}-P_{t-\tau}^{A}\right)\right]\right\}\right] d t+\sigma_{B}^{M} d W_{t}^{M},
\end{aligned}
$$

where $\mu^{i}(>0)$ represents the adjustment speed of asset $i$ 's price by the market maker, $\Sigma^{M}=\left(\begin{array}{c}\sigma_{A}^{M} \\ \sigma_{B}^{M}\end{array}\right)=\left(\begin{array}{cc}\sigma_{A, 1}^{M} & \sigma_{A, 2}^{M} \\ \sigma_{B, 1}^{M} & \sigma_{B, 2}^{M}\end{array}\right)$ is the variance-covariance matrix for 
the market returns, and $W_{t}^{M}=\left(W_{1, t}^{M}, W_{2, t}^{M}\right)^{\prime}$ represent two independent Brownian motions, measuring the demands of noise traders or market noises. They can be correlated with the fundamental shocks $W_{t}^{F}$. Especially, if $\Sigma^{M}$ is a diagonal matrix, then the conditional volatility of one asset cannot be affected by the other asset and hence any spill-over effect in realized volatility cannot be introduced by this term. However, the two assets are still linked via the fundamental correlation and the relative momentum investors.

The asset price model (4.5) is characterized by a nonlinear stochastic delay differential system. The resulting returns are linear functions of three factors, including a fundamental component and two momentum components, in addition to a noise term. $^{13}$

4.2. Co-existing Attractors via Bautin Bifurcation. By assuming a constant fundamental price $F_{t}^{i}=\bar{F}^{i}$ and no market noise $\Sigma^{M}=0$, system (4.5) becomes a deterministic system of delay differential equations, representing the mean processes of market returns of the two risky assets. By exporing the roles of different types of traders, He et al. (2018) obtain the following Proposition 4.1.

Proposition 4.1. For the deterministic model,

(1) it has a unique fundamental steady state $\left(P^{A}, P^{B}\right)=\left(\bar{F}^{A}, \bar{F}^{B}\right)$;

(2) the fundamental steady state is locally asymptotically stable for all $\tau \geq 0$ under condition $\overline{\boldsymbol{C}}$;

(3) the fundamental steady state is locally asymptotically stable for $\tau \in\left[0, \tau_{0}\right)$ and becomes unstable for $\tau>\tau_{0}$ under condition $\boldsymbol{C}$;

(4) it undergoes a Hopf bifurcation at $\tau=\tau_{0}$ under condition $\boldsymbol{C}$. In addition, if $\frac{T}{c_{1}(0)}<0\left(\frac{T}{c_{1}(0)}>0\right)$, then the bifurcation is forward (backward), and the bifurcated periodic solution is stable (unstable) when $c_{1}(0)<0\left(c_{1}(0)>0\right)$. At $c_{1}(0)=0$, a Bautin bifurcation takes place.

Here $\overline{\boldsymbol{C}}, \boldsymbol{C}, T$ and the first Lyapunov coefficient $c_{1}(0)$ are defined in He et al. (2018).

Proposition 4.1 shows that the corresponding deterministic system has bistable dynamics, that is, the coexistence of a stable fundamental steady state and a stable cycle because of a Bautin bifurcation. It means the evolutionary process depends on the market situation, which is used to explain the volatility clustering in the previous section. However, with multi-assets, there exists integration effect among the assets.

\footnotetext{
${ }^{13}$ In a consumption-based asset pricing model where sentiment investors extrapolate the expected returns using all historical returns, Barberis, Greenwood, Jin and Shleifer (2015) show that the return process is linear in the dividend process and the extrapolators' belief. Empirically, Grinblatt and Moskowitz (2004) and Heston and Sadka (2008), among others, find that the historical average returns over a short-run horizon can positively forecast return in the cross-section.
} 


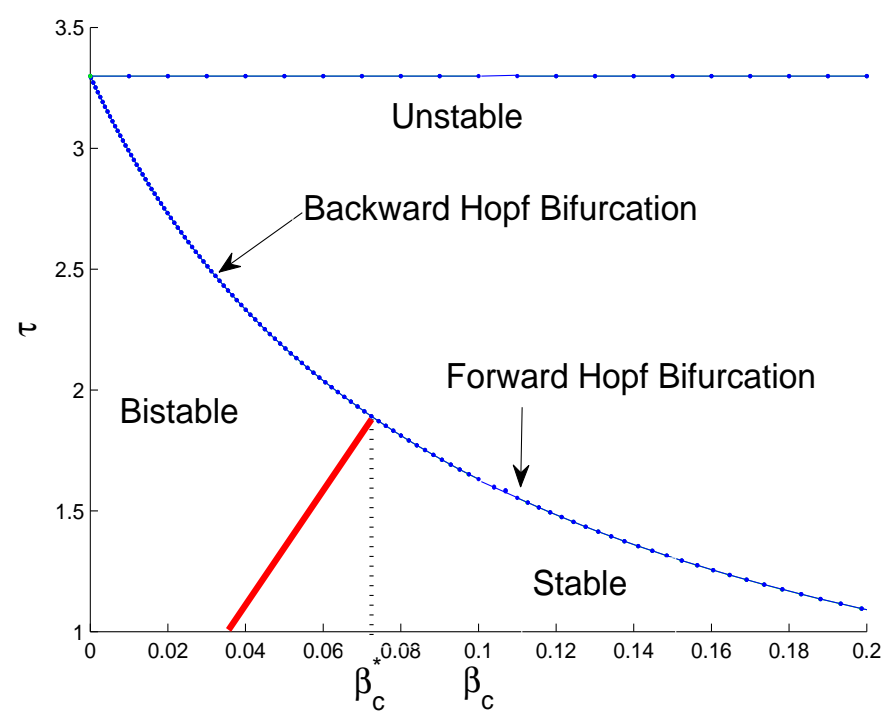

Figure 5. The branch of Hopf bifurcation in $\left(\tau, \beta_{c}\right)$-plane.

Fig. 5 illustrates the extension the Hopf branch bifurcated from the first bifurcation point in $\left(\beta_{c}, \tau\right)$-plane. The upper line is a Hopf bifurcation branch, and the bifurcated periodic solution is unstable. The middle line separates the $\left(\tau, \beta_{c}\right)$-plane into stable and unstable regions of the fundamental steady state, showing that the bifurcation value for $\tau$ decreases when $\beta_{c}$ is increasing. Also $\tau$ tends to the bifurcation value $\tau_{0}$ for decoupled model as $\beta_{c}$ approaches 0 . Through this line, backward or forward Hopf bifurcation occurs, depending on the value of $\beta_{c}$. For any $\beta_{c}<\beta_{c}^{*}$, there exists an interval for $\tau$ (as indicated by the red solid line), on which the system has bistable dynamics characterized by the coexistence of a stable steady state and a stable cycle.

To examine the impact of cross-sectional momentum trading on the bistable dynamics, He et al. (2018) compare three scenarios. In the first scenario, the two separate risky asset prices have forward and stable bifurcations before introducing cross-sectional momentum trading among two risky assets. By allowing the crosssectional momentum trading, the two assets are integrated into one market, generating forward and stable bifurcations. In the second scenario when the two prices have backward and unstable bifurcations before integration, the integrated market can have either backward (unstable) bifurcation or forward (stable) bifurcation. In the third scenario when one risky price has backward (unstable) bifurcation and the other has forward (stable) bifurcation, the integrated market can also have either backward (unstable) bifurcation or forward (stable) bifurcation. These analyses show that the momentum trading can enhance the local stability of the limit cycles (meaning a larger parameter region or basin of the attraction for the bifurcated 
period solution). This provides another destabilizing channel of the cross-sectional momentum trading on market prices, reducing the parameter region of the local stability and enhancing cyclical price oscillation around the fundamental steady state.

4.3. Volatility Spill-over and Empirical Implications. Intuitively, the bistable dynamics is caused by the constraints faced by investors. The wealth and short-sale constraints limit the activity and hence the stabilizing effect of the fundamental traders, reducing the basin of the attraction of the fundamental steady state. When the initial values are far away from the fundamental steady state, the prices tend to depart further away. At the same time, the wealth and short-sale constraints also limit the destabilizing role of the momentum investors. Consequently, the prices cannot explode but settle down at a stable cycle around the fundamental steady state. Therefore, the constraints limit the strengths of both local attractors (the stable steady state and the stable limit cycle), resulting in bistable dynamics.

With the Bautin bifurcation, a locally stable fundamental steady state coexists with a locally stable limit cycle around the fundamental, displaying two very different market states. With small deviations of market price from the fundamental price, market prices tend to be more efficient; however with cyclical fluctuations around the fundamental price, it enhances cross-sectional price momentum, leading to less efficient markets. Triggered by random shocks, market prices then switch stochastically between the two persistent market states. This characterizes the coexistence of seemingly controversial efficient market and price momentum.

He et al. (2018) also provide some empirical implications. First, a strong integration via the cross-sectional momentum can result in comovements in asset prices in opposite directions. Second, cross-sectional momentum trading can give rise to a spillover effect in momentum, and can reduce the correlation of stock returns. More interestingly, the model suggests that cross-sectional momentum trading tends to be self-fulfilling in the sense that it destabilizes the market and generates additional price trends in cross-section.

He et al. (2018) numerically examine the spillover effect for two assets by exploring the joint impact of the integration intensity $\beta_{c}$ and the two noise processes on the market price dynamics. This is illustrated in Fig. 6. Figs. 6 (a) and (b) show that the stochastic price of asset $A$ has greater fluctuations than asset $B$. Figs. 6 (c) and (d) illustrate the prices after the market integration (that is, $\beta_{c}>0$ ). They illustrate that the market integration increases the volatilities for both assets, however, the correlation is reduced comparing to (a) and (b). In fact, the crosssectional momentum trading leads to an opposite movements of the two assets, and hence a smaller correlation after market integration. Therefore market integration increases the volatilities for those two assets, but reduces return correlations. Based 


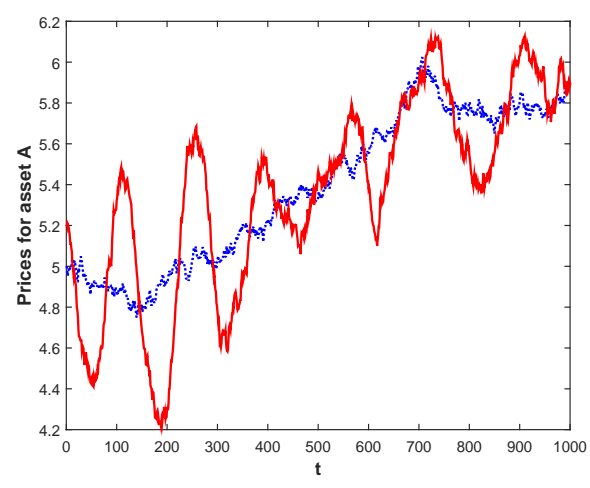

(a) Prices for $A$ when $\beta_{c}=0$

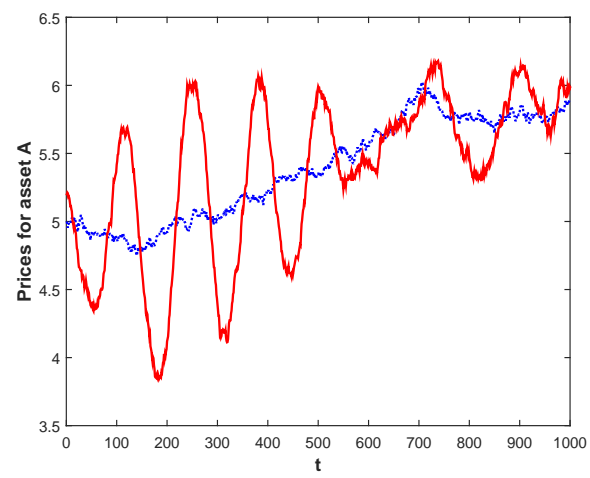

(c) Prices for $A$ when $\beta_{c}=0.015$

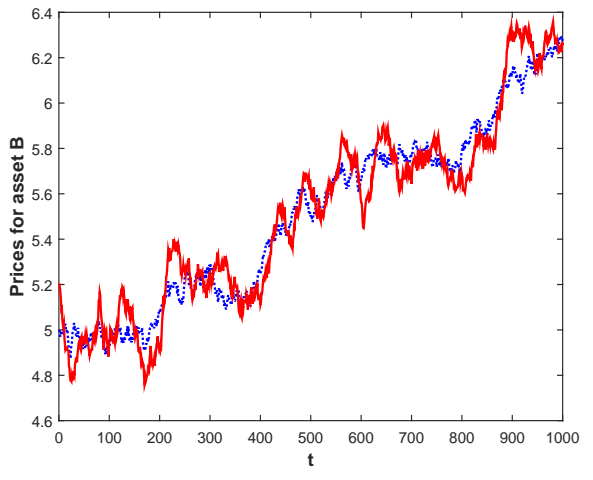

(b) Prices for $B$ when $\beta_{c}=0$

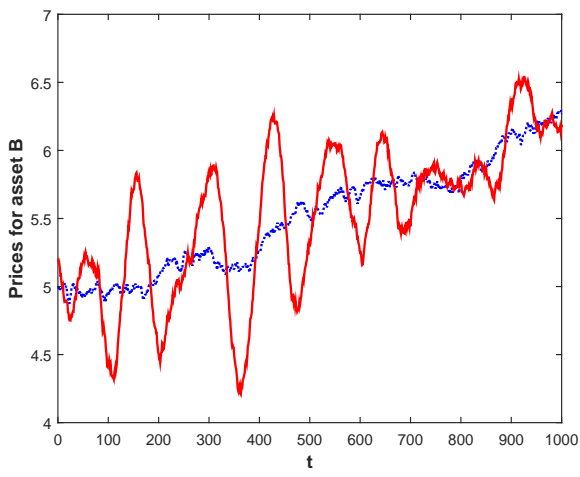

(d) Prices for $B$ when $\beta_{c}=0.015$

Figure 6. The spill-over effect-The time series of log market prices and $\log$ fundamental prices for assets $A$ and $B$.

on the data of S\&P 100 index, NYSE, AMEX and NASDAQ stocks, He et al. (2018) show that the real markets support the model implication that cross-sectional momentum trading trends to reduce the correlations among stocks but destabilizes the market and leads to more significant price trends in cross-section. The empirical findings are consistent with the underlying dynamics.

\section{Exchange Rate Models in Continuous Time}

From the viewpoint of nonlinear dynamical systems, the appearance of multiattractors can be through a pitchfork bifurcation which can directly generates two new stable attractors. This phenomenon is studied by Chiarella, He and Zheng (2013) in a continuous-time model of exchange rates. The exchange rates depend on not only on macroeconomic factors based on domestic-foreign interest rate differential, but also the expectations of boundedly rational portfolio managers who use a weighted average of the expectations of fundamental and trend extrapolation. By analyzing different roles of the macroeconomic factor and investor heterogeneity, 
they show that this simple model can generate very complicated market behavior, including multiple steady state equilibria, deviations of the market exchange rate from the fundamental, and market fluctuations. Numerical analysis demonstrates that the corresponding stochastic model is able to generate typical time series and volatility clustering patterns observed in exchange markets.

5.1. Nonlinear Dynamics of Exchange Rates. Consider an exchange market populated by many portfolio managers who use a weighted average of the expectations of fundamentalists and chartists as specified below. Let $R^{*}$ and $R$ respectively be the foreign and domestic (nominal) rates of interest, $E$ the logarithm of the current exchange rate measured in units of domestic currency per unit of foreign currency, $P$ the logarithm of the domestic price level, $M$ the logarithm of the domestic nominal money supply, and $Y$ the logarithm of the domestic real output. Here $R^{*}, M$ and $Y$ are taken to be exogenous.

The fundamental traders believe that the depreciation of the spot rate should regress to the fundamental value, determined by the interest rate parity condition. That is, the expected rate of exchange depreciation of the fundamentalists $\left(X^{f}\right)$ is assumed to be mean-reverting to the nominal interest rate differential $R-R^{*}$,

$$
\dot{X}^{f}=\beta_{f}\left(R-R^{*}-X^{f}\right),
$$

where $\beta_{f}(>0)$ measures the adjustment speed of the mean-reverting process.

In contrast, the trend extrapolators believe that the change of the log-exchange rate $\left(X^{c}\right)$ follows a weighted average of past changes of the log-exchange rate,

$$
\dot{X}^{c}=\beta_{c}\left(\dot{E}-X^{c}\right)
$$

where $\beta_{c}(>0)$ measures the adjustment speed to the change of the log-exchange rate or the extrapolation rate to the log-exchange rate trend.

The portfolio managers, such as large financial institutions, make their decision by taking a weighted average of the expectations of the fundamental traders and trend extrapolators,

$$
X^{m}=H\left((1-\omega) X^{f}+\omega X^{c}\right), \quad \omega \in[0,1],
$$

where $X^{m}$ is the expected rate of exchange depreciation of the portfolio managers, $\omega$ and $1-\omega$ represent the market fractions that the portfolio managers attach to the expectations of the trend followers and fundamental traders, respectively, and $H(x)=\mu h(x)$ is a function of the expectations mix that is nonlinear due to the cautiousness of the portfolio managers, satisfying

$$
h(0)=0, h^{\prime}(0)=1, \lim _{x \rightarrow \pm \infty} h^{\prime}(x)=0, \text { and } h^{\prime \prime}(x) x<0 \text { for } x \neq 0 .
$$


Note that $\mu=H^{\prime}(0)=\max _{x} H^{\prime}(x)$ measures the weight that the portfolio managers put on the expectations when their expected rates of exchange depreciation are near zero.

A general model of log-exchange rate adjustment is assumed to be determined by portfolio managers and some macroeconomic fundamental factor as follows

$$
\dot{E}=X^{m}+Z,
$$

where $X^{m}$ is defined by (5.3) and $Z$ represents a macroeconomic fundamental factor determined by the nominal interest rate differential,

$$
Z=\beta_{R}\left(R^{*}-R\right),
$$

where $\beta_{R}(>0)$ measures the impact of the fundamental factor on the exchange depreciation in the market. The domestic interest rate is determined by the nominal quantity of money, the real income and the goods price via

$$
\alpha_{1} Y-\alpha_{2} R=M-P, \quad \text { where } \alpha_{1}, \alpha_{2}>0 .
$$

For the goods price, the specification in the original Dornbusch (1976) model is adopted to assume that it follows a sluggish adjustment process according to which the rate of the log-domestic price adjusts to excess demand, which is a decreasing function of the output and domestic nominal interest rate and an increasing function of the relative price $E-P$,

$$
\dot{P}=\rho\left[\beta_{0}-\beta_{1} Y-\beta_{2} R+\beta_{3}(E-P)\right],
$$

where $\rho>0, \beta_{1} \in(0,1), \beta_{2}>0, \beta_{3}>0$ and $\beta_{0}$ is a shift parameter.

To sum up, the model of exchange rate, price and the heterogeneous expectations becomes

$$
\left\{\begin{aligned}
\dot{E} & =H\left((1-\omega) X^{f}+\omega X^{c}\right)+\beta_{R}\left(R^{*}-R\right), \\
\dot{P} & =\rho\left[\beta_{0}-\beta_{1} Y-\beta_{2} R+\beta_{3}(E-P)\right], \\
\dot{X}^{f} & =\beta_{f}\left(R-R^{*}-X^{f}\right), \\
\dot{X}^{c} & =\beta_{c}\left(\dot{E}-X^{c}\right),
\end{aligned}\right.
$$

with $R=\left(\alpha_{1} Y-M+P\right) / \alpha_{2}$. Note that the classical Dornbusch model can be recovered from (5.9) if, under the conditions $\mu=H^{\prime}(0)=\beta_{R}+1$ and $H(x)=\mu x$, it is assumed either $\omega=0$ and $\beta_{f}=\infty$, or $\omega=1$ and $\beta_{c}=\infty$. Also, by choosing $\omega=1, \beta_{c}=\infty, H(x)=\gamma x$ and $\beta_{R}=\gamma$, the model (5.9) yields the Gray and Turnovsky (1979) model with sluggish adjustment in the exchange rate.

Let $\mathcal{S}:=\left(\bar{E}, \bar{P}, \bar{X}^{f}, \bar{X}^{c}\right)$ be a steady state of system (5.9). Then $\mathcal{S}_{0}:=\left(E^{*}, P^{*}, 0,0\right)$ is the fundamental steady state in which the zero interest rate parity condition holds, that is $\bar{R}-R^{*}=0$, where $E^{*}$ and $P^{*}$ are defined by

$$
P^{*}=M-\alpha_{1} Y+\alpha_{2} R^{*}, \quad E^{*}=\frac{1}{\beta_{3}}\left[-\beta_{0}+\beta_{1} Y+\beta_{2} R^{*}+\beta_{3} P^{*}\right] .
$$


It corresponds to the classical equilibrium of the exchange rate in the Dornbusch (1976) model. When $\mu(1-\omega)>\beta_{R}$, there are two other solutions, $\bar{X}^{f}=X_{ \pm}^{*}$, satisfying $X_{-}^{*}<0<X_{+}^{*}$. The condition $\mu(1-\omega)>\beta_{R}$ can be interpreted as either the portfolio managers giving a higher weight (relatively) to the expectations of the fundamentalists, or that they are having a greater impact relative to the macro-environment factor. Correspondingly, system (5.9) has both the fundamental equilibrium and other non-fundamental equilibria, $\mathcal{S}_{ \pm}:=\left(\bar{E}, \bar{P}, \bar{X}^{f}, \bar{X}^{c}\right)=$ $\left(\bar{E}_{ \pm}, \bar{P}_{ \pm}, X_{ \pm}^{*}, 0\right)$ with $\bar{E}_{ \pm}=E^{*}+\left(\frac{\beta_{2}}{\beta_{3}}+\alpha_{2}\right) X_{ \pm}^{*}$ and $\bar{P}_{ \pm}=P^{*}+\alpha_{2} X_{ \pm}^{*}$. Furthermore, the following properties can be obtained.

Proposition 5.1. For the deterministic system (5.9), assume $\beta_{p}<\beta_{f}=\beta_{c}$, and $\mu=1$. Let $\phi:=\beta_{f}=\beta_{c}$ and

$$
\omega^{*}=1+\frac{\beta_{p}^{2}+\beta_{e}\left(\beta_{R}+1\right)-\sqrt{\left(\beta_{p}^{2}-\beta_{e}\left(1+\beta_{R}\right)\right)^{2}+4 \beta_{p} \beta_{e}\left(\beta_{p}+\phi \beta_{R}\right)}}{2 \beta_{p} \phi} .
$$

(a) If $\beta_{R} \leq 1$, then $1-\beta_{R}<\omega^{*}<1$ and the fundamental equilibrium $\mathcal{S}_{0}$ (i) is unstable for $0<\omega<1-\beta_{R}$; (ii) undergoes a pitchfork bifurcation at $\omega=1-\beta_{R}$; (iii) is stable for $1-\beta_{R}<\omega<\omega^{*}$; (iv) undergoes a Hopf bifurcation at $\omega=\omega^{*} ;(v)$ is unstable for $\omega^{*}<\omega<1$.

(b) If $\beta_{R}>1$, then $0<\omega^{*}<1$ and the fundamental equilibrium $\mathcal{S}_{0}$ (i) is stable for $0<\omega<\omega^{*}$; (ii) undergoes a Hopf bifurcation at $\omega=\omega^{*}$; (iii) is unstable for $\omega^{*}<\omega<1$.

Proposition 5.1 shows how changes in the weight $\omega$ lead to different market behavior. When $\omega=0, \mathcal{S}_{0}$ undergoes a pitchfork bifurcation at $\beta_{R}=\mu$. When $\omega=1$, $\mathcal{S}_{0}$ undergoes a Hopf bifurcation at $\beta_{p}=\beta_{c}$. For $0<\omega<1$, the stability and the induced bifurcations are illustrated by the bifurcation plot of the log-exchange rate $E$ in terms of the parameter $\omega$ in Figure 7 . It shows different types of bifurcations when the market expectation is dominated by either one of the expectation schemes. When $\mathcal{S}_{0}$ loses its stability for $\omega<1-\beta_{R}$ because of the appearance of two stable non-fundamental equilibria $\left(\mathcal{S}_{ \pm}\right)$from a pitchfork bifurcation, the expectations of the fundamentalists are responsible for the induced pitchfork bifurcation, while the expectations of the chartists are responsible for the induced Hopf bifurcation at $\omega=\omega^{*}$. Also, a mixture of the two expectations can stabilize an otherwise unstable steady state $\mathcal{S}_{0}$ when $\omega \in\left(1-\beta_{R}, \omega^{*}\right)$. This stabilizing effect of combining different types of expectations is also shared by asset pricing models with heterogeneous beliefs (see, for example, Chiarella and He, 2002).

5.2. Stochastic Dynamics and Mechanism Analysis. The model analyzed above is entirely deterministic. However, in the real exchange market, there always exist some noise factors which have an important influence on the exchange 


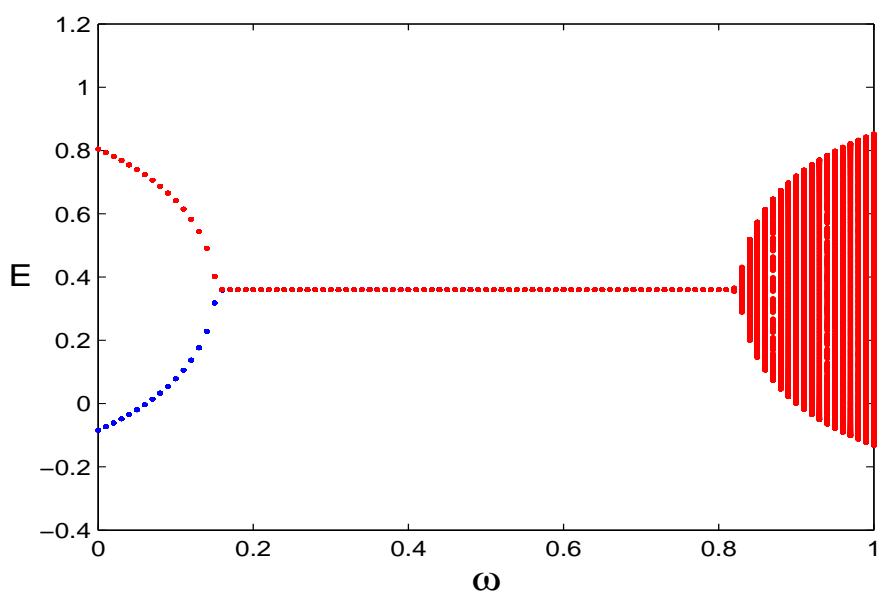

Figure 7. The bifurcation of the log-exchange rate $E$ in terms of the parameter $\omega \in[0,1]$ for $\mu=1, \beta_{R}=0.85, \beta_{f}=0.8$ and $\beta_{c}=0.8$. The fundamental steady state undergoes a pitchfork bifurcation at $\omega=1-\beta_{R}=0.15$, and a Hopf bifurcation at $\omega=\omega^{*}=0.8286$.

rate dynamics. To capture this effect, the first equation in (5.9) is replaced by the stochastic differential equation

$$
d E=\left[H\left((1-\omega) X^{f}+\omega X^{c}\right)+\beta\left(R^{*}-R\right)\right] d t+\sigma_{E} d W_{E}
$$

where $W_{E}$, representing the market noise, is a Wiener process on a probability space $(\Omega, \mathscr{F}, \mathscr{P})$ with zero drift and unit variance per unit time and $\sigma_{E}>0$ measures the intensity of the market noise.

In addition, in order to capture the different dynamics induced by the change in the weighting parameter in the deterministic model, the market fraction of the fundamentalists or chartists $(1-\omega$ or $\omega)$ will not be treated as constant but allowed to randomly change ${ }^{14}$. Let $\mu=1, \beta_{R}=0.85, \beta_{f}=0.8$ and $\beta_{c}=0.8$ as in Figure 7. Based on Proposition 5.1, it is uncovered that changes in $\omega$ lead to the existence of three types of dynamics with a stable fundamental steady state (Case $\mathcal{F}$, for example $\omega=0.25$ ), two stable non-fundamental steady states (Case $\mathcal{P}$, for example $\omega=0.1$ ) and a stable limit cycle (Case $\mathcal{H}$, for example $\omega=0.85$ ), see Figure 7 . To allow for all three types of behavior, the market fraction $\omega$ is assumed to follow a simple discrete random choice process satisfying

$$
d \omega_{t}=\left(\xi-\omega_{t-}\right) d N_{t},
$$

\footnotetext{
${ }^{14}$ Another mechanism for changing weights could be based on some fitness measure, which has been widely used in asset pricing models with heterogeneous beliefs following Brock and Hommes (1998) and De Grauwe and Grimaldi (2006) in exchange markets.
} 
where $N_{t}$ is a compound Poisson process with jump intensity $\lambda$. This means that when $d N_{t}=0$, the market fraction remains at the original level $\omega_{t-}$, while when $d N_{t}=1$, the market fraction $\omega_{t+}=\xi$ follows a Markov chain with three discrete states $\left\{\omega_{\mathcal{P}}, \omega_{\mathcal{F}}, \omega_{\mathcal{H}}\right\}$ and the transition probability matrix $\mathbf{P}$ given by

$$
\begin{aligned}
& \mathcal{P} \quad \mathcal{F} \quad \mathcal{H} \\
& \mathbf{P}=\left(\begin{array}{ccc}
0.9 & 0.1 & 0 \\
0.25 & 0.4 & 0.35 \\
0 & 0.95 & 0.05
\end{array}\right) \begin{array}{l}
\mathcal{P} \\
\mathcal{F} . \\
\mathcal{H}
\end{array}
\end{aligned}
$$

The size of the noises is given by $\sigma_{E}=0.0158$ per trading period and $\lambda=0.05$ (meaning that, on average, there is one jump for every 20 trading periods).

As discussed by De Grauwe and Grimaldi (2006), a great deal of empirical research has uncovered many puzzles or anomalies in exchange markets, for example disconnection from fundamental factors, excess volatility, volatility clustering and fat tails. Based on the stochastic model with the deterministic skeleton (5.9) in company with two noise processes (5.11) and (5.12), Figure 8(a) shows a typical time series of the log-exchange rate and Figure 8(b) shows the corresponding return series. They display persistent deviation of the market exchange rate from the (constant) fundamental exchange rate and irregular switching between phases of low volatility with returns close to zero and phases of high volatility. This is because the weight between the fundamentalists and chartists changes stochastically, as illustrated in Figure 9. For different weights, the exchange rate has different stability properties. When $\omega=0.25$, the fundamental exchange rate converges to the fundamental steady state equilibrium and the corresponding time series shows such a converging tendency. However, when $\omega=0.10$, the fundamental equilibrium is unstable and another two stable non-fundamental steady states co-exist. In this case, the time series undergoes a deviation from the fundamental equilibrium. When $\omega=0.85$, there is a stable limit cycle around the unstable fundamental equilibrium for the deterministic model and the time series shows a fluctuation around the fundamental equilibrium level. Not surprisingly, adding the dynamical noise to the system destroys the regularity of the exchange rate around the (non-)fundamental steady state or the cycle, and leads to an irregular switching between phases of low volatility (where the fundamental equilibrium is stable) and phases of high volatility (where the fundamental equilibrium is unstable), and to deviation from the underlying fundamental equilibrium most of the time. Furthermore, the density of the log-exchange rate is bimodal as observed in Figure 8(c) and the return of the exchange rate in Figure 8(b) shows volatility clustering. In addition, the absolute and squared returns in Figures $8(\mathrm{~g})$ and $(\mathrm{h})$ display strong positive autocorrelations (ACs), but the ACs of the return in Figure 8(f) are insignificant (except the first 


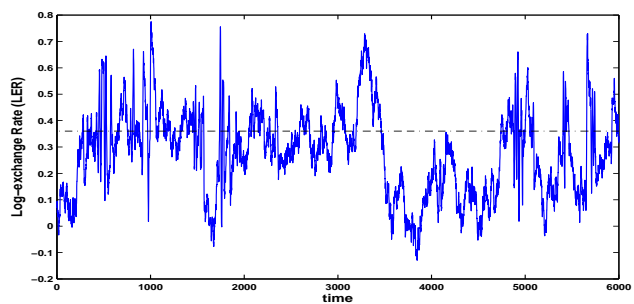

(a) Time series of log-exchange rate (LER)

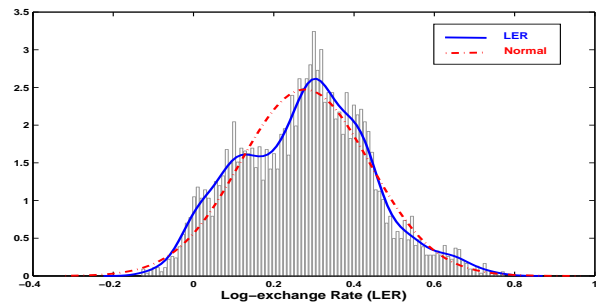

(c) Density of LER

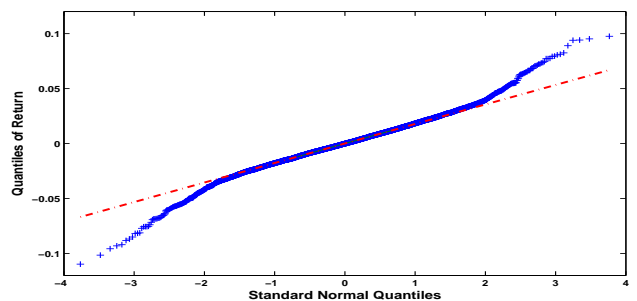

(e) QQ-plot of $r$

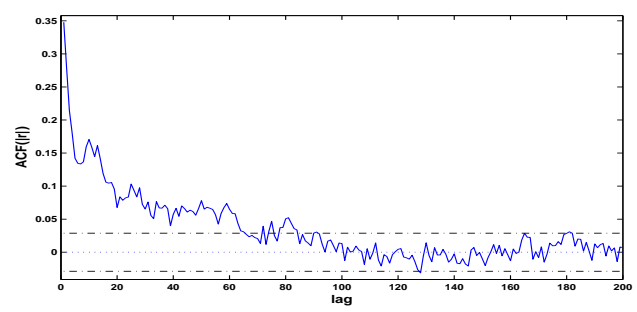

(g) ACF of $|r|$

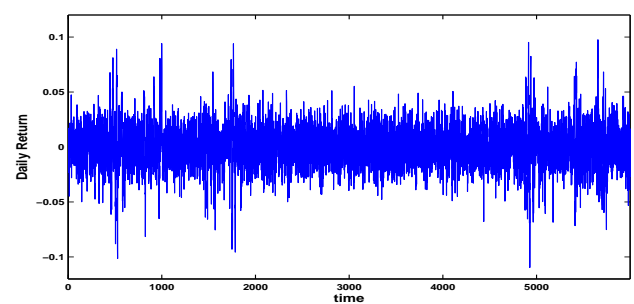

(b) Time series of daily return $(r)$

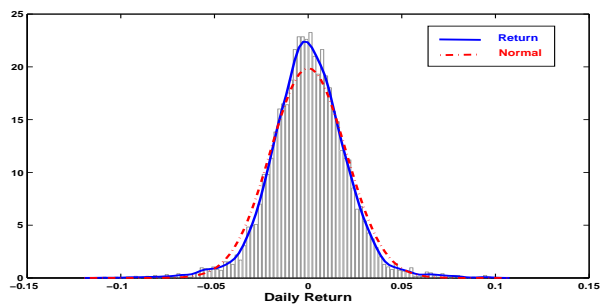

(d) Density of $r$

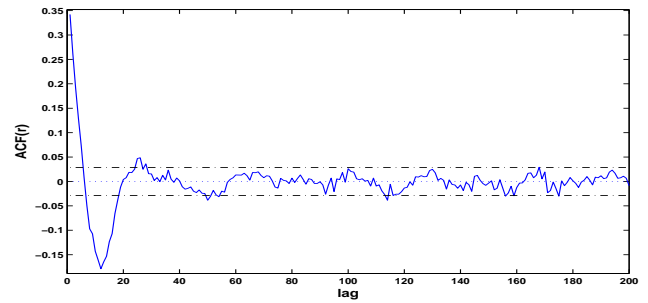

(f) ACF of $r$

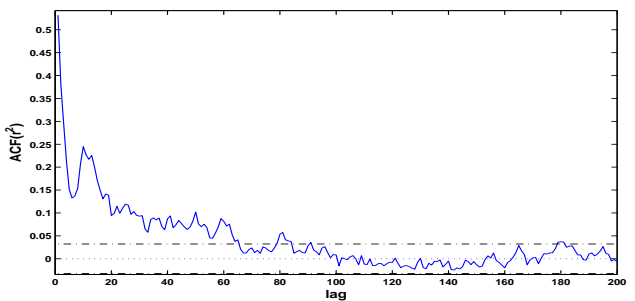

(h) $\mathrm{ACF}$ of $r^{2}$

Figure 8. Statistical analysis of the simulation results.

few time lags). The distribution of the exchange rate return in Figures 8(d) and (e) is non-normal with fat tails. These effects correspond to most of the stylized facts observed in exchange markets. Overall the results indicate that heterogeneous beliefs in exchange markets can potentially explain the puzzles and anomalies of exchange rates to a certain extent and the interaction between the fundamentalists and chartists is a potential source of the mechanism generating some of those characteristics. 


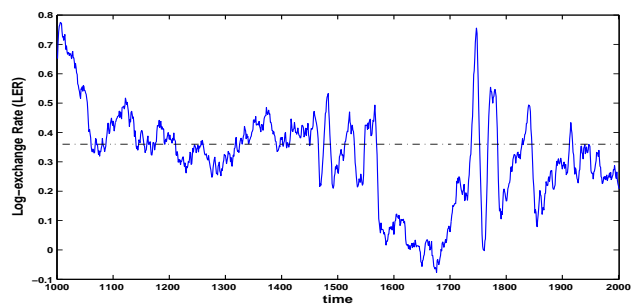

(a) Log-exchange rate (LER)

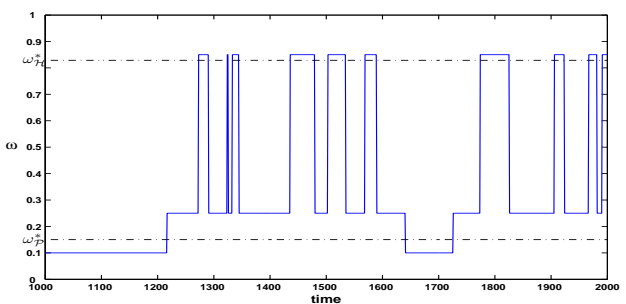

(b) Market fraction of the chartists $(\omega)$

Figure 9. Time series of the log-exchange rate and the market fraction of the chartists from Time 1000 to Time 2000.

\section{Conclusion and Future Research}

In the last twenty years, the literature on heterogeneous agent models (HAMs) in finance has experienced significant growth. HAMs have proved their promising perspectives and explanatory power of various market anomalies and, in particular, the stylized facts of financial markets. Different from traditional empirical finance and financial econometrics, HAMs provide insights into economic mechanisms and driving forces of these stylized facts. This paper selectively reviews the latest development of HAMs from a nonlinear dynamics approach perspective.

In a discrete time setting, a simple asset pricing model with two types of boundedly rational traders, fundamentalists and trend followers, and noise traders, can provide the coexistence of two attractors, a locally stable steady state and a locally stable invariant circle. The interaction of the deterministic dynamics and noise processes can endogenously generate volatility clustering and long range dependence in volatility markets. Economically, volatility clustering occurs when neither the fundamental nor trend following traders dominate the market, which corresponds to the coexistence of the two attractors, and when traders switch more often between the two strategies. The coexistence of multi-attractors can also be generated when the fundamental steady state is locally stable but globally unstable because of the appearance of a new, nonfundamental and stable steady state coming from a saddle-node bifurcation. Zheng et al. (2017) explore this to model housing market dynamics, which have only very recently been investigated from the perspective of HAMs.

Compared with discrete time, a continuous time setting has advantages to be able to provide a unified framework to deal with historical prices. In a continuous-time multi-assets HAM, investment constraints can lead to the coexistence of a locally stable fundamental steady state and a locally stable limit cycle around the fundamental, characterized by a Bautin bifurcation. This provides a mechanism for market prices to switch stochastically between the two persistent but very different 
market states, leading to the coexistence and time-varying dominance of seemingly controversial efficient market and price momentum over different time periods. The rich dynamics of continuous time HAMs can be extended to model other financial markets such as foreign exchange markets. Foreign exchange rates not only rely on macroeconomic factors but also have an investor heterogeneity component. The driving macroeconomic factor is the domestic-foreign interest rate differential, while the investor heterogeneity is described by the expectations of boundedly rational portfolio managers who use a weighted average of the expectations of fundamentalists and chartists. The simple model is able to generate complicated market behavior, including the existence of multiple steady-state equilibria, deviations of the market exchange rate from the fundamental one and market fluctuations.

The models reviewed in this paper can be developed further in future researches. While the heterogeneity of investors in financial markets has been widely accepted and documented in the literature, there is also large literature on social interactions and social networks. Incorporating social interactions and social networks to HAMs would be helpful for examining their impact on financial markets and asset pricing. $\mathrm{He}$, Li and Shi (2016) recently develop a simple evolutionary model of asset pricing and population dynamics to incorporate social interactions among investors with heterogeneous beliefs on information uncertainty. They show that social interactions can lead to mis-pricing and coexistence of multiple steady state equilibria, generating two different volatility regimes, bi-modal distribution in population dynamics, and stochastic volatility. As pointed out by Hirshleifer (2015), [T] he time has come to move beyond behavioral finance to social finance. This would provide a fruitful area of research in the near future.

It is promising to study housing market dynamics from the perspective of HAMs. The existing models are mainly aimed at qualitative or quantitative investigations of the role of price extrapolation in generating house price fluctuations. One way to expand this is to explain existing home sales. Existing home transaction in general exceeds new home sales, hence is more important for both price and financing. Another is to consider patterns of house price distributions because the prices of some central places, such as Beijing, have a profound influence for house prices in its neighborhood.

\section{REFERENCES}

Admati, A. (1985), 'A noisy rational expectations equilibrium for multi-asset security markets', Econometrica 53, 629-657.

Admati, A. and Pfleiderer, P. (1987), 'Viable allocations of information in financial markets', Journal of Economic Theory 43, 76-115.

Alfarano, S., Lux, T. and Wagner, F. (2005), 'Estimation of agent-based models: The case of an asymmetric herding model', Computational Economics 26, 19-49. 
Allen, H. and Taylor, M. (1990), 'Charts, noise and fundamentals in the London foreign exchange market', Economic Journal 100, 49-59.

Amromin, G. and Sharpe, S. (2014), 'From the horses mouth: Economic conditions and investor expectations of risk and return', Management Science 60, 845-866.

Bacchetta, P., Mertens, E. and van Wincoop, E. (2009), 'Predictability in financial markets: What do survey expectations tell us?', Journal of International Money and Finance 28, 406-426.

Barberis, N. (2013), Financial innovation: Too much or too little?, in M. Haliassos, ed., 'Psychology and the Financial Crisis of 2007-2008', Cambridge: MIT Press.

Barberis, N., Greenwood, R., Jin, L. and Shleifer, A. (2015), 'X-CAPM: An extrapolative capital asset pricing model', Journal of Financial Economics 115, 1-24.

Bauer, C., De Grauwe, P. and Reitz, S. (2009), 'Exchange rate dynamics in a target zone-A heterogeneous expectations approach', Journal of Economic Dynamics and Control 33(2), 329 -344 .

Beja, A. and Goldman, M. (1980), 'On the dynamic behavior of prices in disequilibrium', Journal of Finance 35, 235-247.

Brock, W. and Hommes, C. (1997), 'A rational route to randomness', Econometrica 65, 1059-1095.

Brock, W. and Hommes, C. (1998), 'Heterogeneous beliefs and routes to chaos in a simple asset pricing model', Journal of Economic Dynamics and Control 22, 1235-1274.

Chen, S.-H., Chang, C. and Du, Y. R. (2012), 'Agent-based economic models and econometrics', Knowledge Engineering Review 27(2), 187-219.

Chiarella, C. (1992), 'The dynamics of speculative behaviour', Annals of Operations Research 37, 101-123.

Chiarella, C., Dieci, R. and Gardini, L. (2002), 'Speculative behaviour and complex asset price dynamics', Journal of Economic Behavior and Organization 49, 173-197.

Chiarella, C., Dieci, R. and He, X. (2009), Heterogeneity, Market Mechanisms and Asset Price Dynamics, Elsevier, pp. 277-344. in Handbook of Financial Markets: Dynamics and Evolution, Eds. Hens, T. and K.R. Schenk-Hoppé.

Chiarella, C. and He, X. (2002), 'Heterogeneous beliefs, risk and learning in a simple asset pricing model', Computational Economics 19, 95-132.

Chiarella, C. and He, X. (2003a), 'Dynamics of beliefs and learning under $a_{l}$-processes - The Heterogeneous case', Journal of Economic Dynamics and Control 27, 503-531.

Chiarella, C. and He, X. (2003b), 'Heterogeneous beliefs, risk and learning in a simple asset pricing model with a market maker', Macroeconomic Dynamics 7, 503-536.

Chiarella, C., He, X. and Hommes, C. (2006), 'A dynamic analysis of moving average rules', Journal of Economic Dynamics and Control 30, 1729-1753.

Chiarella, C., He, X. and Zheng, M. (2013), 'Heterogeneous expectations and exchange rate dynamics', European Journal of Finance 19, 392-419.

Daniel, K. and Moskowitz, T. (2016), 'Momentum crashes', Journal of Financial Economics 122, 221-247.

Day, R. and Huang, W. (1990), 'Bulls, bears and market sheep', Journal of Economic Behavior and Organization 14, 299-329.

De Grauwe, P., Dewachter, H. and Embrechts, M. (1993), Exchange Rate Theory: Chaotic Models of Foreign Exchange Markets, Blackwell.

De Grauwe, P. and Grimaldi, M. (2006), 'Exchange rate puzzles: A tale of switching attractors', European Economic Review 50, 1-33. 
Di Guilmi, C., He, X. and Li, K. (2014), 'Herding, trend chasing and market volatility', Journal of Economic Dynamics and Control 48, 349-373.

Dieci, R., Foroni, I., Gardini, L. and He, X. (2006), 'Market mood, adaptive beliefs and asset price dynamics', Chaos, Solitons and Fractals 29, 520-534.

Dieci, R. and He, X. (2018), Heterogeneity agent models in finance, in C. Hommes and B. LeBaron, eds, 'Handbook of Computational Economics', Vol. 4, Elsevier, chapter 5, pp. 257-328.

Dieci, R. and Westerhoff, F. (2012), 'A simple model of a speculative housing market', Journal of Evolutionary Economics 22, 303-329.

Dornbusch, R. (1976), 'Expectations and exchange rate dynamics', Journal of Political Economy 84(6), 1161-1176.

Fama, E. (1970), 'Efficient capital markets: A review of theory and empirical work', Journal of Finance 25, 383-423.

Fama, E. (2014), 'Two pillars of asset pricing', American Economic Review 104, 1-20.

Farmer, J. and Joshi, S. (2002), 'The price dynamics of common trading strategies', Journal of Economic Behavior and Organization 49, 149-171.

Gaunersdorfer, A. and Hommes, C. (2007), A Nonlinear Structural Model for Volatility Clustering, Springer, Berlin/Heidelberge, pp. 265-288. in Long Memory in Economics, Eds. Teyssiere, G. and A. Kirman.

Goldstein, I. and Yang, L. (2015), 'Information diversity and complementarities in trading and information acquisition', Journal of Finance 70, 1723-1765.

Gray, M. and Turnovsky, S. (1979), 'The stability of exchange rate dynamics under perfect myopic foresight', International Economic Review 20(3), 643-660.

Greenwood, R. and Shleifer, A. (2014), 'Expectations of returns and expected returns', Review of Financial Studies 27, 714-746.

Grinblatt, M. and Moskowitz, T. (2004), 'Predicting stock price movements from past returns: The role of consistency and tax-loss selling', Journal of Financial Economics 71, 541-579.

Grossman, S. and Stiglitz, J. (1980), 'On the impossibility of informationally efficient markets', American Economic Review 70, 393-408.

He, X. (2014), Recent developments in asset pricing with heterogeneous beliefs and adaptive behavior of financial markets, Springer, pp. 3-34. in Global Analysis of Dynamical Models in Economics and Finance, Eds. G.I Bischi, C. Chiarella, and I. Sushko.

He, X. and Li, K. (2012), 'Heterogeneous beliefs and adaptive behaviour in a continuous-time asset price model', Journal of Economic Dynamics and Control 36, 973-987.

He, X. and Li, K. (2015a), 'Profitability of time series momentum', Journal of Banking and Finance 53, 140-157.

He, X., Li, K. and Shi, L. (2016), Social interaction and asset pricing, Technical report, Quantitative Finance Research Centre, University of Technology, Sydney.

He, X., Li, K. and Wang, C. (2016), 'Volatility clustering: A nonlinear theoretical approach', Journal of Economic Behavior and Organization 130, 274-297.

He, X., Li, K. and Wang, C. (2018), Time-varying economic dominance through bistable dynamics, Research Paper 390, Quantitative Finance Research Centre.

He, X. and Li, Y. (2007), 'Power law behaviour, heterogeneity, and trend chasing', Journal of Economic Dynamics and Control 31, 3396-3426.

He, X. and Li, Y. (2008), 'Heterogeneity, convergence and autocorrelations', Quantitative Finance $8,58-79$. 
He, X. and Li, Y. (2015b), 'Testing of a market fraction model and power-law behaviour in the DAX 30', Journal of Empirical Finance 30, 1-17.

He, X. and Li, Y. (2017), 'The adaptiveness in stock markets: testing the stylized facts in the DAX 30', Journal of Evolutionary Economics 27(5), 1071-1094.

He, X. and Westerhoff, F. (2005), 'Commodity markets, price limiters and speculative price dynamics', Journal of Economic Dynamics and Control 29, 1577-1596.

Heckman, J. (2001), 'Micro data, heterogeneity, and evaluation of public policy: Nobel lecture', Journal of Political Economy 109(4), 673-748.

Heston, S. and Sadka, R. (2008), 'Seasonality in the cross-section of stock returns', Journal of Financial Economics 87, 418-445.

Hirshleifer, D. (2015), 'Behavioral finance', Annual Review of Financial Economics 7, 133-159.

Hommes, C. (2001), 'Financial markets as nonlinear adaptive evolutionary systems', Quantitative Finance 1, 149-167.

Hommes, C. (2006), Heterogeneous Agent Models in Economics and Finance, Vol. 2 of Handbook of Computational Economics, North-Holland, pp. 1109-1186. in Agent-based Computational Economics, Eds. Tesfatsion, L. and K.L. Judd.

Hommes, C. (2013), Behavioral Rationality and Heterogeneous Expectations in Complex Economic Systems, Cambridge University Press, New York.

Hommes, C. and Wagener, F. (2009), Complex Evolutionary Systems in Behavioral Finance, number Chapter 4 in 'Handbooks in Finance', North-Holland, pp. 217-276. in Handbook of Financial Markets: Dynamics and Evolution, Eds. Hens, T. and K. Schenk-Hoppé.

Jegadeesh, N. and Titman, S. (1993), 'Returns to buying winners and selling losers: Implications for stock market efficiency', Journal of Finance 48, 65-91.

Jegadeesh, N. and Titman, S. (2001), 'Profitability of momentum strategies: An evaluation of alternative explanations', Journal of Finance 56, 699-720.

Kuchler, T. and Zafar, B. (2016), Personal experiences and expectations about aggregate outcomes, working paper, New York University and Federal Reserve Bank of New York.

LeBaron, B. (2006), Agent-based Computational Finance, Vol. 2 of Handbook of Computational Economics, North-Holland, pp. 1187-1233. in Agent-based Computational Economics, Eds. Tesfatsion, L. and K.L. Judd.

Li, Y., Donkers, B. and Melenberg, B. (2010), 'Econometric analysis of microscopic simulation models', Quantitative Finance 10, 1187-1201.

Lux, T. (1995), 'Herd behaviour, bubbles and crashes', Economic Journal 105, 881-896.

Lux, T. (2009), Stochastic Behavioural Asset Pricing and Stylized Facts, Elsevier, pp. 161-215. in Handbook of Financial Markets: Dynamics and Evolution, Eds. Hens, T. and K.R. SchenkHoppé.

Menkhoff, L. (2010), 'The use of technical analysis by fund managers: International evidence', Journal of Banking and Finance 34, 2573-2586.

Moskowitz, T., Ooi, Y. H. and Pedersen, L. H. (2012), 'Time series momentum', Journal of Financial Economics 104, 228-250.

Pagan, A. (1996), 'The econometrics of financial markets', Journal of Empirical Finance 3, 15-102.

Sargent, T. (1993), Bounded Rationality in Macroeconomics, Clarendon Press, Oxford.

Shefrin, H. (2005), A Behavioral Approach to Asset Pricing, Academic Press Inc., London.

Shiller, R. (2003), 'From efficient markets theory to behavioral finance', Journal of Economic Perspectives 17(1), 83-104. 
Shiller, R. (2014), 'Speculative asset prices', American Economic Review 104, 1486-1517.

Vissing-Jorgensen, A. (2004), 'Perspectives on behavioral finance: Does irrationality disappear with wealth? Evidence from expectations and actions', NBER Macroeconomics Annual 18, 139194.

Westerhoff, F. (2009), Handbook of Research on Complexity, Edward Elgar, Cheltenham, chapter Exchange rate dynamics: A nonlinear survey, pp. 287-325.

Zeeman, E. (1974), 'The unstable behavior of stock exchange', Journal of Mathematical Economics 1, 39-49.

Zheng, M., Liu, R. and Li, Y. (2018), 'Long memory in financial markets: A heterogeneous agent model perspective', International Review of Financial Analysis 58, 38-51.

Zheng, M., Wang, H., Wang, C. and Wang, S. (2017), 'Speculative behavior in a housing market: Boom and bust', Economic Modelling 61, 50-64. 